\title{
Crosstalk between intracellular and extracellular signals regulating interneuron production, migration and integration into the cortex
}

\author{
Elise Peyre ${ }^{1,2 \dagger}$, Carla G. Silva ${ }^{1,2+}$ and Laurent Nguyen ${ }^{1,2,3 *}$ \\ ' GIGA-Neurosciences, University of Liège, Liège, Belgium, ${ }^{2}$ Interdisciplinary Cluster for Applied Genoproteomics (G/GA-R), \\ University of Liège, Liège, Belgium, ${ }^{3}$ Wallon Excellence in Lifesciences and Biotechnology, University of Liège, Liège, Belgium
}

OPEN ACCESS

Edited by:

Yoko Arai,

Université Paris Diderot, France

Reviewed by:

Christine Métin,

Institut National de la Santé et de la

Recherche Médicale, France

Diego Matias Gelman,

Instituto de Biologia y Medicina

Experimental, Argentina

*Correspondence:

Laurent Nguyen,

GIGA-Neurosciences, Quartier Hôpital, University of Liège, Tour B36, Avenue Hippocrate 15, 4000 Liège,

Belgium

Inguyen@ulg.ac.be

${ }^{t}$ These authors have contributed equally to this work

Received: 19 December 2014 Accepted: 19 March 2015

Published: 14 April 2015

Citation:

Peyre E, Silva CG and Nguyen L (2015) Crosstalk between intracellular and extracellular signals regulating interneuron production, migration and integration into the cortex.

Front. Cell. Neurosci. 9:129. doi: 10.3389/fncel.2015.00129
During embryogenesis, cortical interneurons are generated by ventral progenitors located in the ganglionic eminences of the telencephalon. They travel along multiple tangential paths to populate the cortical wall. As they reach this structure they undergo intracortical dispersion to settle in their final destination. At the cellular level, migrating interneurons are highly polarized cells that extend and retract processes using dynamic remodeling of microtubule and actin cytoskeleton. Different levels of molecular regulation contribute to interneuron migration. These include: (1) Extrinsic guidance cues distributed along migratory streams that are sensed and integrated by migrating interneurons; (2) Intrinsic genetic programs driven by specific transcription factors that grant specification and set the timing of migration for different subtypes of interneurons; (3) Adhesion molecules and cytoskeletal elements/regulators that transduce molecular signalings into coherent movement. These levels of molecular regulation must be properly integrated by interneurons to allow their migration in the cortex. The aim of this review is to summarize our current knowledge of the interplay between microenvironmental signals and cell autonomous programs that drive cortical interneuron porduction, tangential migration, and intergration in the developing cerebral cortex.

Keywords: interneurons, cortex, migration, progenitors, nucleokinesis, branching

\section{Introduction}

During mouse embryogenesis, cortical interneurons (cINs) are generated in the ventral subpallium. Distinct proliferative regions can be identified in this area, including the lateral ganglionic eminence (LGE), the medial ganglionic eminence (MGE), the caudal ganglionic eminence (CGE) and the preoptic area (POA). While the MGE, CGE and POA contribute to the generation of cortical interneurons (cINs) (Flames et al., 2007; Rubin et al., 2010), the LGE is mostly involved in striatal and olfactory bulb histogenesis (Yun et al., 2003). These distinct subpallial regions differ

Abbreviations: CGE, caudal ganglionic eminence; cIN, cortical interneuron; CP, cortical plate; CR, calretinin; dMGE, dorsal medial ganglionic eminence; F-actine, fibrilar actine; G-actine, globular actine; IP, intermediate progenitor; IZ, intermediate zone; LGE, lateral ganglionic eminence; MGE, medial ganglionic eminence; MT, microtubule; MZ, marginal zone; NPY, neuropeptide Y; POA, preoptic areo; PTM, post-translational modification; PV, parvalbumin; SAP, subapical progenitor; SNP short neuroal precursor; SP, subplate; SST, somatostatin; SVZ, subventricular zone; VIP, vasointestinal peptide; vMGE, ventral medial ganglionic eminence; VZ, ventricular zone. 
in progenitor domain composition and in the ability to generate IN subtypes characterized by specific networks of transcription factors. In addition to genetic programs, diffusing molecules also participate in shaping the timing, space and specificity of cIN subtype production. Indeed, at the earlier stages of corticogenesis, molecules acting as mitogens and morphogens induce genetic programs eventually leading to the expansion of proliferative regions, specification and maturation of cINs. In rodents, cINs migrate long distances to reach their final destination. Again, they are under control of genetic programs and signaling cascades triggered by extracellular cues that work together to produce a synchronized, harmonious and directed movement toward the cortex. At the cellular level, these informations are integrated and translated by the cytoskeleton into appropriate cellular behavior. After settling at their final location, cINs integrate and organize in coherent networks. Here we will review the current understanding of how genetic programs intermingle with extracellular signaling pathways to achieve the production, migration and network integration of INs in the cortex.

The exact number of cIN subtypes remains debated, mainly due to the diversity in their morphological, molecular and functional properties (Petilla Interneuron Nomenclature et al., 2008). In this review, a simplified nomenclature combining molecular and physiological properties of cINs will be used. According to this nomenclature (Gelman and Marin, 2010), the large variety of cIN subtypes will fall in one of four major groups: (a) fast spiking, parvalbumin (PV)-expressing cINs; (b) burst spiking or adapting non-fast spiking somatostatin (SST)-expressing cINs; (c) non-fast spiking and fast adapting calretinin (CR)- and/or vasointestinal peptide (VIP)-expressing cINs; (d) rapidly adapting neuropeptide Y (NPY)- and/or reelin-expressing cINs. Most studies discussed here used rodents as experimental model. They have been useful in the understanding of the physiopathology underlying cortical interneuron development. We will finalize by giving example of how these findings fit with what starts being known about the production, migration and cortical integration of GABAergic neurons in primate and human.

\section{Generation and Specification of Cortical Interneurons}

\section{Role of Morphogens in Establishing Ventral Identity}

MGE histogenesis starts at around embryonic day (E) 9, followed by the generation of LGE at E10 and CGE at E11 (Smart, 1976). GEs histogenesis requires a complex interplay between morphogens and transcription factors to ventralize the structure and promote IN production. Sonic hedgehog $(\mathrm{SHH})$ and fibroblast growth factors (FGFs) contribute to the dorso-ventral patterning and subpallium development (Jessell, 2000; Briscoe and Ericson, 2001; Ingham and McMahon, 2001). Shh is widely expressed in the prospective MGE by E9 and by E12 its expression spreads to the mantle zone of the MGE and POA (Echelard et al., 1993). Cell responsiveness to SHH greatly depends on the action of the transcription factors of the GLI family that can, in their constitutively cleaved forms, act as transcriptional repressors in the absence of SHH signaling. Conversely if uncleaved, they function as transcriptional activators in the presence of $\mathrm{SHH}$ (Bai et al., 2004; Pan et al., 2006). The current understanding postulates that $\mathrm{SHH}$ signaling is required to counteract GLI3 repressor activity therefore contributing to the positioning of the dorsoventral boundary (Figure 1). At early stages of brain development, $\mathrm{SHH}$ prevents dorsalization of the ventral telencephalon, allowing the subsequent formation of the GEs. This is in contrast with the role of GLI proteins in the spinal cord where these factors act as activators by directly promoting ventral patterning (Rallu et al., 2002; Bai et al., 2004). Downstream effectors of SHH signaling are also required for ventral development. They include smoothened, the low-density lipoprotein receptor-related protein 2 (LRP2) or megalin and the multifunctional transmembrane protein Cdo (Fuccillo et al., 2004; Spoelgen et al., 2005; Zhang et al., 2006). In Shh knockout mouse models, rescue of the ventral telencephalon by compound Gli3 removal gives the indication that other genes might act independently or downstream of Shh (Rallu et al., 2002). Several studies provide evidence that FGFs act downstream of SHH and can directly induce ventral gene expression in dorsal telencephalic explants when $\mathrm{SHH}$ signaling is inhibited (Aoto et al., 2002; Ohkubo et al., 2002; Kuschel et al., 2003; Gutin et al., 2006; Rash and Grove, 2007). Since SHH promotes Fgf expression (Martynoga et al., 2005), FGFs are considered mandatory effectors of $\mathrm{SHH}$ signaling (Figure 1). The forkhead G1 factor (FOXG1) is the main generator of direct ventralization within the forming ventral telencephalon as it induces expression of Fgf8 (Martynoga et al., 2005) in the MGE or FGF15 in the CGE (Borello et al., 2008). Foxg1 acts in concert with FGF signaling, forming a positive feedback loop (Shimamura et al., 1995; Martynoga et al., 2005). Foxg1 expression is independent of the direct action of SHH but impaired in the absence of Shh due to the increased repressor activity of GLI3 (Rash and Grove, 2007).

\section{Transcription Factors acting in Concert with Morphogens in the MGE}

The MGE contributes to the production of $50-60 \%$ of the total population of cINs in the mouse (Pleasure et al., 2000; Butt et al., 2005; Wonders and Anderson, 2006). On top of the hierarchical MGE SHH- and FGF-dependent organizers is Nkx2-1 transcription factor (Sussel et al., 1999; Gutin et al., 2006; Storm et al., 2006; Fogarty et al., 2007; Xu et al., 2008, 2010). Nkx2-1 itself maintains Shh expression within the early MGE, a process depending on FoxA2/HNF-3 $\beta$ transcription factor (Sussel et al., 1999) (Figure 1). Moreover, early removal of $N k x 2.1$ from MGE progenitors re-specifies INs into early LGE medium spiny neuron identity, while its late removal leads to acquisition of CGE IN profile (Butt et al., 2008). Nkx2-1 is no longer detected in mice that lack expression of both Fgfr1 and Fgfr2 (Gutin et al., 2006). The analysis of the expression of several transcription factors within the ventricular zone (VZ) of the MGE have led to the proposal that this region can be compartmentalized into five different progenitor domains (Flames et al., 2007). The dorsal region of the MGE (dMGE) preferentially gives rise to somatostatin (SST)expressing cINs. In contrast, the ventral part of the MGE (vMGE) was shown to mostly generate paravalbulin (PV)-expressing cINs. 


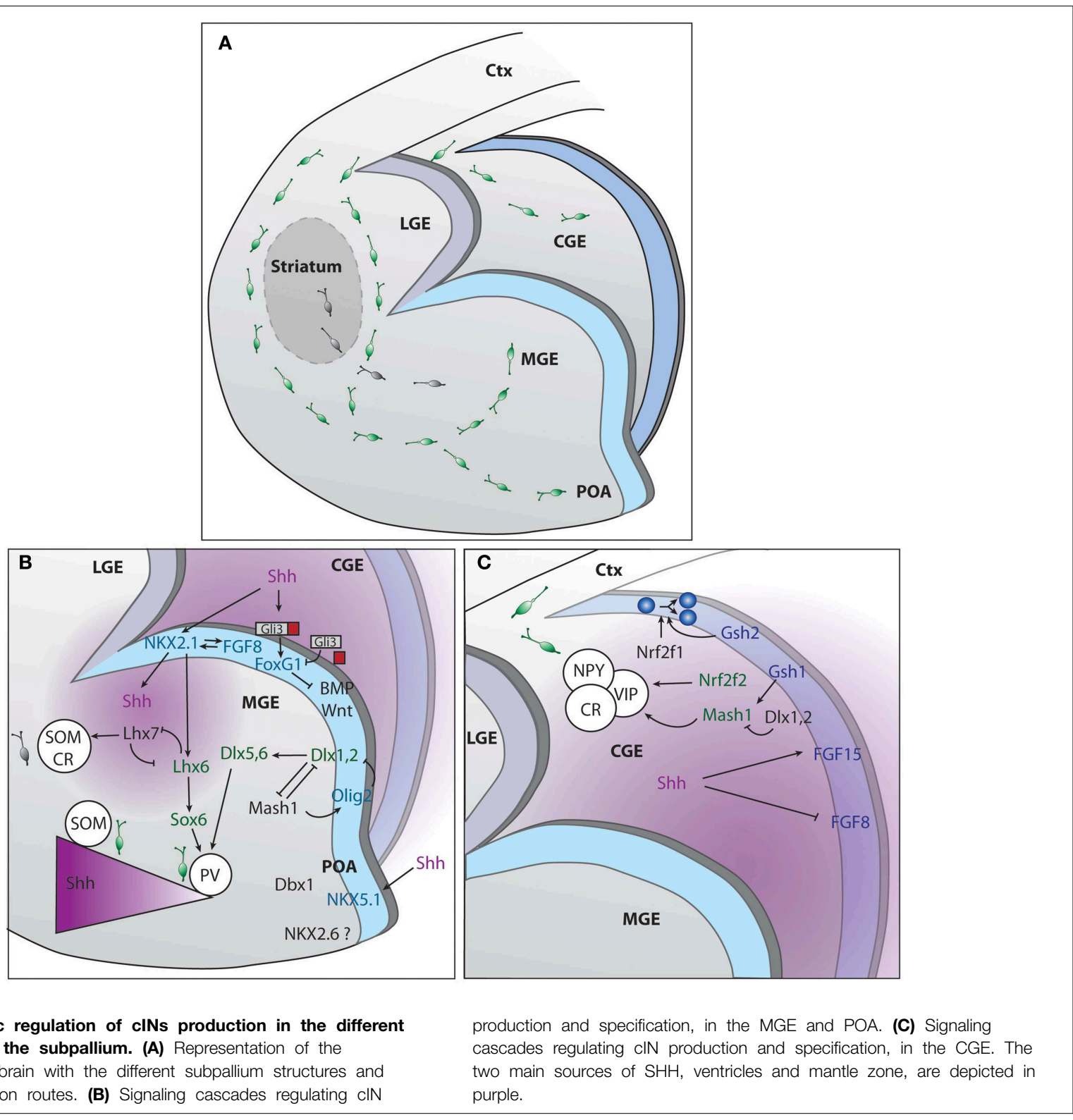

Since Nkx2-1 expression promotes the specification of both SST and PV cIN subtypes, it was suggested that the SHH gradient determines the final fate of interneurons. High levels of $\mathrm{SHH}$ signaling would favor the generation of SST-expressing cINs at the expenses of PV-expressing cINs (Xu et al., 2010). Consistently, high expression levels of SHH effectors were found in the dMGE (Wonders et al., 2008). More recently, it was demonstrated that neurons from the mantle zone are an additional source of $\mathrm{SHH}$ (Flandin et al., 2011). They play a relevant role in maintaining a high SHH gradient in the dMGE, far away from the VZ. SHH production by mantle neurons was shown to require expression of Lhx6 (Flandin et al., 2011), a direct target of Nkx2-1, also implicated in PV or SST fate acquisition. In the absence of $\operatorname{Lh} x 6$, NPY fate was promoted at the expenses of PV or SST (Liodis et al., 2007; Zhao et al., 2008). It was also shown that disruption of the gene encoding FGF receptor 1 ( Fgfrl) lead to a loss of
Lhx6 and $\operatorname{Lhx} 8(7)$ expression, both necessary for the formation of MGE-derived INs (Fragkouli et al., 2005; Gutin et al., 2006; Liodis et al., 2007) and maturation of PV-cINs (Smith et al., 2014). Other genes act downstream of or in concert with $N k \times 2-1$. For example, high levels of $\operatorname{Lh} x 8(7)$ expression shifts the fate of cINs toward globus pallidus GABAergic neurons and into cholinergic INs from the striatum (Zhao et al., 2003; Fragkouli et al., 2005). Sox6 expression is required for the generation of the appropriate number of PV and SST INs as demonstrated in studies using germline and conditional knockout mice (Azim et al., 2009; Batista-Brito et al., 2009). In these mice models, a concomitant increase of NPY cINs was observed (Azim et al., 2009; BatistaBrito et al., 2009). Sox6 acts downstream Lhx6 and is expressed continuously within the MGE from postmitotic progenitor stage until adulthood and is implicated in the placement and maturation of PV and ST cINs (Batista-Brito et al., 2009). Dlx genes 
also contribute to cINs specification and maturation. Dlx genes expression is temporally regulated, following the sequence: $D l \times 2$, Dlx1, Dlx5, and Dlx6 (Liu et al., 1997; Eisenstat et al., 1999). Dlx1/2 gene seems to be particularly important for the acquisition of SST, calretinin (CR), NPY and reelin fates (Cobos et al., 2005) as its absence leads to an abnormal expression of cortical markers in the ventral telencephalon (Long et al., 2009a,b). The expression of a wide range of transcription factors in the MGE progenitors from the VZ and subventricular zone (SVZ) as well as non-transcription factor proteins involved in migration and cortical integration are also under the control of $D l \times 1 / 2$ (Long et al., 2009a). For example, Dlx1/2 has a repressor activity over Arx transcription factor, required for MGE differentiation. In their absence, cIN migration is blocked, resulting in accumulation of cells in the GEs and reduced numbers of INs in the cortex (Colombo et al., 2007). In addition, $D l \times 1 / 2$ genes are also required for the delayed expression of $D l \times 5 / 6$ genes (Anderson et al., 1997; Yun et al., 2002; Long et al., 2009b), particularly important for the establishment of PV subtype identity (Wang et al., 2010). Furthermore, Dlx1/2 tightly control the generation of oligodendrocytes in the forebrain by repressing Olig2 (Petryniak et al., 2007). More precisely, the choice between neuronal and glial fate involves cross-regulation between Mash1 or Acsl1 and Dlx genes. Mash1 binds to and represses the regulatory DNA elements in the intergenic region of $D l x 1 / 2$ (Parras et al., 2007). In Mash1 mutants, $D l x 1 / 2$ expression is expanded in the VZ/SVZ (Casarosa et al., 1999; Horton et al., 1999; Yun et al., 2002; Poitras et al., 2007). Conversely Mash1 expression is increased in the VZ/SVZ of Dlx1/2 mutants (Yun et al., 2002). Thus, the role of Mash1 consists in restricting the number of $D l x$-expressing progenitors (Petryniak et al., 2007).

\section{Transcription Factors and Morphogens Shaping the Generation of cINs in the CGE}

CGE contributes to the generation of $30-40 \%$ of all cortical interneurons. Several studies have demonstrated that CGE derived interneurons acquire either a CR and/or VIP (Pleasure et al., 2000; Butt et al., 2005) or reelin identity (Miyoshi et al., 2010). Gsh or Gsx homeobox TFs act at the top of the genetic network involved in CGE cell specification (Figure 1). Gsh2 is particularly relevant for the generation of CR bipolar cINs (Xu et al., 2010). Interestingly, Gsh1 and Gsh2 are co-expressed but have antagonist functions within the CGE, Gsh 2 promoting progenitor state and Gsh1 promoting neuronal differentiation (Pei et al., 2011). Interestingly, the control of the choice between proliferation and differentiation by Gsh genes seems to involve the downstream target Mash1 (Fode et al., 2000). In Mash1 loss of function there is premature differentiation of progenitors located in the SVZ and precocious expression of $D l x$ genes (Casarosa et al., 1999; Yun et al., 2002), downstream effectors. On the other hand, overexpression of Mash1 contributes to cell type specification (Fode et al., 2000). Dlx 1 and $D l \times 2$ are co-expressed in subsets of progenitor cells and contribute to cell maturation by downregulating Gsh2/Mash1 (Yun et al., 2002). Other CGE transcription factors include Nrf2f1and Nrf2f2 or Couptf1 and Couptf2, respectively, as well as SP8. These genes are however not exclusive from CGE, as they have been identified in the dMGE and POA (Lodato et al., 2011a). Nrf2f1 is required for proper progenitor proliferation and necessary for generation of interneuron diversity in the cortex (Lodato et al., 2011a). Nrf2f2 is important for directing interneurons through a caudal migratory path (Cai et al., 2013). SP8 function in the hierarchy of CGE specification/maturation is yet unknown (Ma et al., 2012).

\section{The POA Produces a Reduced Number of Diverse cIN Subtypes}

The POA is the most ventral region of the developing subpallium and it has been shown to generate around $10 \%$ of GABAergic INs. Using a Cre line driven by $N k \times 5$ - 1 or $H m x 3$, a gene exclusive from POA, gives rise to a small population (around 4\%) of multipolar GABAergic cells (Gelman et al., 2009). Another 5\% of total INs is also produced by progenitors present in this region, characterized by their expression of the transcription factor Dbxl. Fate mapping and in utero transplantation demonstrated that POA generates diverse cINs subtypes (Gelman et al., 2011). In terms of molecular markers expression, the cells generated by the POA resemble the ones originating from the CGE (Gelman et al., 2009). Shh and Nkx2-1 but not Lhx6 are also expressed in the POA (Flames et al., 2007). Dbx1 and Nkx6-2 are respectively markers of the dorsal and ventral POA (see Figure 1). The function of these genes remains, however, elusive.

\section{Progenitors and Proliferation in the Ventral Subpallium}

Ventral telencephalon expansion and generation of a great diversity of cINs relies on the proliferation of pools of progenitors. The molecular rules governing cell proliferation in the ventral telencephalon as well as the characterization of the distinct cIN progenitor behavior has just started to be unveiled. For some time it was anticipated that GE progenitors would display a proliferative behavior similar to progenitors in the cerebral cortex (Ross, 2011). This view relied on anatomical and cumulative bromodeoxyuridine (BrdU) experiments. These studies were important as they served identifying both $\mathrm{VZ}$ and SVZ as two distinct proliferative compartments (Sheth and Bhide, 1997). The lack of selective markers for the SVZ and the superposition of proliferating and migrating cINs hampered for some time detailed studies aiming at characterizing the cellular biology of cell division of ventral progenitors. Improvement of molecular tools and imaging techniques overcame these limitations. For example, an elegant study by Brown and colleagues used a clonal approach to understand how cINs were generated within these regions. Low concentration of retrovirus expressing GFP was injected in the ventricle of E11 embryos. In order to specifically infect INs progenitor cells, the virus entry receptor was expressed under the control of Nkx2-1 (Brown et al., 2011). They found that cINs are produced as spatially organized clonal units and clonally related INs form spatially isolated cluster in the neocortex. They identified the presence of radial glia (RG) in the VZ of MGE and POA that undergo interkinetic nuclear migration and divide asymmetrically in the VZ to self-renew and produce intermediate progenitors (IPs) or differentiating cINs. Using time-lapse microscopy, Pilz et al. (2013) proposed a more complex hierarchical classification for ventral progenitors. RG cells sit at the 
base of this classification and divide asymmetrically to generate both an amplifying and a self-renewal branch. These cells give rise to short neural precursors (SNPs). Both RG and SNPs generate subapical progenitors (SAPs) which in turn divide to produce basal radial glia (bRG) or basal progenitors (BPs). Basal radial glia and BPs contribute to the great SVZ expansion. Mash1 levels were shown to control the numbers of SAPs (Pilz et al., 2013). Although this study was performed in the LGE, such hierarchical complexity might be expected for the entirety of the ventral telencephalon.

\section{Molecular Regulation of Ventral Proliferation}

Studies performed by Vidaki et al. (2012) showed that classical proteins displaying a role in dorsal proliferation, such as Rasrelated C3 botulinum toxin substrate 1 (Rac1), are also important regulators of $N k \times 2-1$-expressing MGE progenitor division. In the absence of Rac1, cyclin D proteins levels are reduced and similarly low levels of Retinoblastoma $(\mathrm{Rb})$ phosphorylation is detected. Cortical interneuron progenitors are thus blocked from completing cell cycle (halted in G1 phase) and accumulate in the GEs. Interestingly, the lack of cyclin D2 in SVZ progenitors lead to the production of lower number of PV but not SST cIN subtypes (Glickstein et al., 2007a,b, 2009), suggesting that cell division and cell fate acquisition are linked events (Glickstein et al., 2007b; Ross, 2011). Rb family proteins and the closely related protein $\mathrm{p} 107$, play a role in cell proliferation by regulating the activity of E2F transcription factors, notably E2F4 a transcription repressor (Trimarchi and Lees, 2002). Deficiency of E2F4 expression impairs the selfrenewal of neuronal precursor cells (Ruzhynsky et al., 2007) and results in loss of ventral telencephalic structures. The underlying mechanism involves a dramatic loss of Shh, Nkx2-1, and Dlx2 expression.

Acting extracellularly, morphogens such as $\mathrm{SHH}$ and FGFs can also potentially act as mitogens (Hebert and Fishell, 2008). SHH-mediated proliferation is regulated in space and time (Blaess et al., 2006). If progenitors are exposed to SHH during the peak of neurogenesis, it will enhance proliferation, whereas exposure during the post-neurogenic period maintains cells in the undifferentiated state (Rowitch et al., 1999). Downstream effectors of SHH regulating the cell cycle are N-myc (Kenney et al., 2003), cyclin D1 (Kenney and Rowitch, 2000), E2f1 and E2f2 (Oliver et al., 2003). The induction of N-myc occurs through GLI proteins and its stabilization depends on phosphatidylinositol3-kinase (PI3-K) (Kenney et al., 2004; Sjostrom et al., 2005). FGFs control cell cycle length mainly during G1 phase. In a cell culture model, addition of FGF2 results in G1 phase shortening and an increase in the number of proliferative divisions by E14-E16 (Lukaszewicz et al., 2002). In vivo, Fgf8 controls ventral telencephalon size mainly in rostral regions (Storm et al., 2006). This effect mainly relied on the control over progenitor survival (Storm et al., 2006). Deletion of Fgf3 in addition to Fgf8 further decreased the telencephalic size, indicating that both genes act in synergy (Theil et al., 2008). Fgf15 controls progenitor differentiation at earlier developmental stages by promoting cell cycle shortening and exit, an effect opposite of what was observed at later stages (Borello et al., 2008). Neurotransmitter receptors are another class of diffusible molecules that control cell proliferation in the developing telencephalon (Cameron et al., 1998; Nguyen et al., 2001; Owens and Kriegstein, 2002a,b). cIN precursors and progenitors appear to be sources of gamma aminobutyric acid (GABA) (Bellion and Metin, 2005). Indeed, the extracellular GABA concentrations in the GEs may be as high as $0.5 \mu \mathrm{M}$ (Cuzon et al., 2006). Proliferating cIN precursors also display detectable levels of GABA synthetizing enzymes and functional $\mathrm{GABA}_{\mathrm{B}}$ receptors (Maric et al., 2001) as well as GABA and chloride transporters (Laurie et al., 1992; Ma and Barker, 1995). Glutamate is also present in the telencephalic germinal zones where it acts as mitogen. In the cortex, both GABA and glutamate where shown to decrease proliferation in the SVZ probably by reducing DNA synthesis as a consequence of membrane depolarization and $\mathrm{Ca}^{2+}$ increase (LoTurco et al., 1995; Haydar et al., 2000), in opposition to what was observed on VZ progenitors (Haydar et al., 2000). Glutamate actions were found to be diverse and depend on the glutamate receptor subtype involved in the signaling. For example, DNA synthesis inhibition occurs when $\alpha$-amino-3-hydroxy-5-méthylisoazol-4-propionate (AMPA)/ kainate (KA) receptors are activated (LoTurco et al., 1995). N-methyl-D-aspartate (NMDA) receptor-dependent signaling instead promotes proliferation of striatal neural progenitors (Sadikot et al., 1998; Luk et al., 2003). The ERK (Extracellular Signal-Regulated Kinase)-PI3K pathway is triggered downstream NMDA receptor activation to control proliferation of striatal progenitors (Luk et al., 2003). Variation in glutamate concentration (Haydar et al., 2000) and interaction between glutamate receptormediated and growth factors-mediates signaling pathways (Dobbertin et al., 2000) might further contribute for a differential responsiveness of distinct progenitors. The action of morphogens and/or mitogens can be disrupted by many environmental agents and by epigenetic modifications during the period of corticogenesis. It is thus of utmost interest to fully characterize the signaling cascades triggering ventral proliferation.

\section{Migration of Cortical Interneurons}

During development, cINs migrate over long distances to reach the cortex and settle within cortical layers. Migrating cINs are highly polarized cells harboring a branched and dynamic leading process that terminates in a growth cone-like structure. They also possess a membrane protrusion at the rear of the cell called trailing process. While migrating, cINs display a stereotyped cyclic movement (Figure 2A). First, there is an extension of branches emanating from the leading process and as one of the branches stabilizes, a transient swelling forms close to the cell body where the centrosome and Golgi apparatus are displaced (Bellion et al., 2005). Then, cINs move forward by sudden and fast nuclear translocation into the swelling, an event called nucleokinesis. The jumping behavior of cINs characterizes its migration pattern and distinguishes it from the treadmill-like movement observed in a large range of cells. Finally, the trailing process is retracted and the cycle repeats. cINs can significantly change the direction of migration by inverting polarity, the trailing process extending and becoming the new leading process while the older leading process undergoes retraction (Nadarajah 

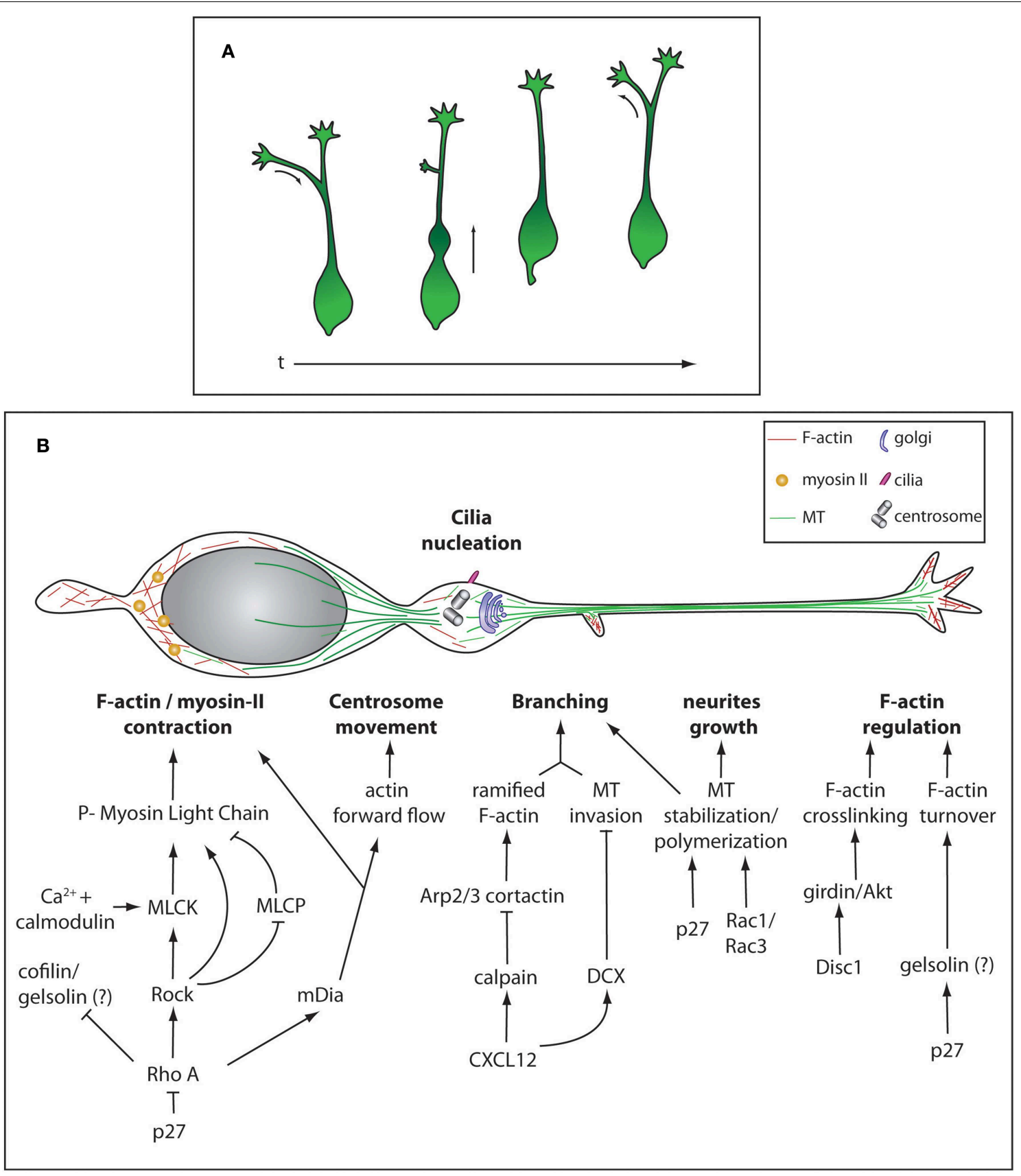

FIGURE 2 | Morphological remodeling during cIN migration and cytoskeleton regulation. (A) Different stereotypical morphologies during of cIN migration over time. (B) Representation of the cytoskeleton and some cellular components of a migrating cIN. Cytoskeleton-regulating cascades are represented in specific cellular compartments, not meaning they are exclusive to these different compartments. et al., 2002) (Figure 2A). All these dynamic phases heavily rely on cytoskeleton remodeling.

\section{Molecular Regulation of the Cytoskeleton in Migrating cINs} cINs Migration and Nucleokinesis

In cINs, a microtubule (MT) "cage" surrounds the nucleus and a large array of MTs connects this structure to the centrosome
(Tanaka et al., 2004; Higginbotham and Gleeson, 2007; Godin et al., 2012) (Figure 2B). MTs are nucleated ahead of the nucleus to guide centrosome movement and docking to the cell membrane. At the membrane, the mother centriole is then able to grow a cilium allowing the cell to sense extracellular signals such as SHH (Baudoin et al., 2012). It was previously considered that the MT network was responsible for generating forces required for nucleokinesis, through dynein-dynactin directed 
motor movement. This type of MT-generated forces has been described for migration of projection neurons and cerebellar granule cells where MT-associated proteins Lissencephaly-1 (Lis1) and Doublecortine (DCX) couple MT to the nucleus (Tanaka et al., 2004; Nasrallah et al., 2006; Tsai et al., 2007). Similarly, cINs depleted for Lis-1 show a reduced rate of migration (McManus et al., 2004). It was however demonstrated in vitro that the chemical destabilization of the MT network does not completely abolish nucleokinesis (Schaar and McConnell, 2005; Baudoin et al., 2008; Martini and Valdeolmillos, 2010). Instead, acto-myosin contractibility is necessary for nuclear movement, as shown by experiments in which non-muscle myosin-II-mediated contraction was blocked (Bellion et al., 2005; Schaar and McConnell, 2005; Baudoin et al., 2008; Martini and Valdeolmillos, 2010). Myosin-II is enriched behind the nucleus during nuclear translocation, where F-actin also shows a strong accumulation (Bellion et al., 2005; Schaar and McConnell, 2005; Martini and Valdeolmillos, 2010) (Figure 2B). Acto-myosin cytoskeleton is also necessary to promote centrosome separation from the nucleus upon swelling formation and for the dynamic remodeling of growth cones (Metin et al., 2006). Altogether, this strongly suggests that the forward movement occurring during nucleokinesis arises from pushing forces generated by acto-myosin contraction at the rear of the nucleus, together with limited MT- generated pulling forces (He et al., 2010; Steinecke et al., 2014a). Although well studied in the context of radial migration of projection neurons, the molecular cascade regulating acto-myosin cytoskeleton during tangential migration is not as well described. In many cell types the Rho family GTPases including Rho, Rac, and cell division control protein 42 homolog (CDC42) have been implicated in the regulation of acto-myosin contractility (reviewed in Heasman and Ridley, 2008; Govek et al., 2011). In cINs, modification of RhoA activation levels by loss of function of its inhibitor p27Kip1 leads to migration defects (Besson et al., 2004) due to myosin-II hyperactivation (Godin et al., 2012). Active RhoA, in its GTP bound state, regulates migration by activating the downstream kinase Rho-associated protein kinase (ROCK) and mDia but also by inhibiting cofilin, an actin severing enzyme (Kawauchi et al., 2006; Nguyen et al., 2006; Godin et al., 2012). ROCK promotes acto-myosin contraction using different mechanisms. It can directly phosphorylate Myosin Light Chain (MLC), inhibit Myosin Light Chain Phosphatase (MLCP) or activate Myosin Light Chain Kinase (MLCK) (Amano et al., 1996; ChrzanowskaWodnicka and Burridge, 1996; Kimura et al., 1996; Ishizaki et al., 1997). MLCK activation leads to acto-myosin contraction by phosphorylating MLC. MLCK activity is modulated by its cofactor calmodulin, a calcium-activated protein (Gallagher et al., 1997). mDia is an actin nucleator that helps producing long filaments of actin fibers (Higashida et al., 2004) (Figure 2B). Interestingly, mutant mice for $m D i a 1$ show impaired tangential migration, but no defects in radial cortical dispersion. In this animal model the anterograde actin flow that moves the centrosome forward as well as F-actin accumulation at the rear of the nucleus are impaired. In contrast, actin dynamics in the growth cone is normal (Shinohara et al., 2012). This argues for a differential regulation of cytoskeleton-generated forces in different subcellular compartments where ROCK and mDia cooperate to grant proper acto-myosin dynamics during cIN migration. F-actin turnover is a crucial parameter in acto-myosin dynamics as inhibition of F-actin severing was shown to stabilize the leading process and can lead to cell migration arrest (Chai et al., 2009a,b). In INs, partial inactivation of cofilin in mice lacking $p 27$ does not result in strong accumulation of F-actin, suggesting that F-actin severing can be mediated by redundant mechanisms, for example by the action of gelsolin (Godin et al., 2012) (Figure 2B).

\section{cINs Leading Process, Branching, and Growth Cone Regulation}

cINs navigate in their environment using a branched leadingprocess bearing dynamic growth cones. When a chemo-repulsive cue is sensed, the growth cone collapses and the branch is consequently retracted. In parallel, another branch is stabilized and it determines the new direction of migration (Martini et al., 2009). Leading process branching requires the coordination of both acto-myosin and MT networks. During this process a new membrane protrusion is formed thanks to the underlying ramified F-actin meshwork organized by cortactin and Actin-related proteins 2/3 (Arp2/3) (Spillane et al., 2011; Lysko et al., 2014). Then, invasion by unbundled and freely spreading MTs stabilizes the protrusion and allow the emergence of the branch. Recent evidence shows that fine-tuning of cIN branching is negatively regulated by CXCL12 or SDF-1 (Lysko et al., 2014). Binding of CXCL12 to its receptor CXCR4, results in decreased levels of cAMP and de-repression of calpain and DCX expression. This intracellular signaling has a double effect on the cytoskeleton: generation of straight F-actin fibers by calpain-mediated proteolysis of cortactin and MT bundling by DCX. Membrane protrusions are thus less likely to form in the absence of a branched actin meshwork and be stabilized by bundled MTs. Accordingly, hyperbranching is observed in cINs lacking DCX (Kappeler et al., 2006; Friocourt et al., 2007; Lysko et al., 2014) (Figure 2B). Proper regulation of MT dynamics is also essential for cIN tangential migration as neurite growth is depending on the establishment of new MT-networks. For example, in p27kip1 mutant, neurite growth defects are observed and cannot be fully rescued by modulating the acto-myosin contraction mediated by the RhoA pathway (Godin et al., 2012). Interestingly it was shown that p27kip1 acts also as a MT-associated protein (MAP) thanks to its prolinerich domain that promotes MT polymerization both in vivo and in vitro. This indicates that MT polymerization is an essential parameter in modulating neurite growth and migration properties of cINs (Godin et al., 2012). Similarly, the establishment of a long leading process also requires MT stabilization. In Rac1/Rac3 mutant mice, migrating cINs show a hyper-branched phenotype similar to the one observed in Dcx knockout mice as well as a reduced leading process length. This is also accompanied by MTs harboring less post-translational modifications (PTMs), frequent on stable and long-lived MTs. The phenotype was partially rescued by treating the cells with taxol, a MT stabilizing agent, indicating that establishment of a correct migration needs a minimal amount of stable MTs (Tivodar et al., 2014) (Figure 2B). Growth cone shape is modulated by both MT polymerization that generates pushing forces on the plasma membrane and by actomyosin network underlying pulling forces on the leading edge. 
Actin undergoes polymerization and depolymerisation activity and acto-myosin contraction leads to the generation of an actin retrograde flow. The balance between these two networks will either allow growth or retraction of the leading process (Martini et al., 2009). Behind the leading edge, interactions between cell surface and migration substrate together with actin retrograde flow generate traction forces. Importantly, sectioning the leading tip or locally inhibiting acto-myosin contraction halts nucleokinesis, highlighting the role of this region in force generation (He et al., 2010). Actin cytoskeleton is regulated at the leading edge by Disc1 and cINs deficient for this protein accumulate less F-actin together with less phosphorylated Girders of Actin filaments (girdin) and Protein kinase B (Akt), crosslinkers of actin filaments (Steinecke et al., 2014a). Girdin targeting to to the leading tip requires interaction with Discl (Steinecke et al., 2014a). Mice mutant for Disc1 or Lis1, display decreased level of acetylation, a marker of stable MTs in the growth cone. This suggests that stable bundles of MTs are not properly entering this structure and are important to grant the proper shape to the growth cone (Gopal et al., 2010; Steinecke et al., 2014a) (Figure 2B).

\section{cINs Migration Substrate}

Adhesion to a migration substrate allows cINs to generate actomyosin forces as well as to organize cellular polarization and directionality. cINs seem to use cell-cell interaction to migrate along bundles of fibers of the corticofugal system invading the GEs (Metin and Godement, 1996). TAG-1 or contactin-2, a member of the immunoglobulin superfamily expressed by the corticofugal axons was proposed to mediate cell-cell contact between migrating cINs and corticofugal fibers as inhibition of TAG-1 leads to a strong reduction of cIN migration in vitro (Denaxa et al., 2001). However, in vivo TAG-1 does not play a role during migration cINs (Denaxa et al., 2005). In cINs, proteins displaying a role in adhesion such as talin, paxilin or Focal Adhesion Kinases (FAKs) are also calpain substrates (Franco and Huttenlocher, 2005). Calpain inhibition reduces migration speed despite the increased levels of F-actin (Lysko et al., 2014), implying that local adhesion turnover by cleavage is primordial for correct migration. Finally, N-cadherin, a homophilic cell adhesion molecule has been shown to be necessary during tangential migration (Luccardini et al., 2013). N-cadherin not only promotes cINs motility in vitro and in vivo, likely by promoting adhesion through the acto-myosin cytoskeleton (Giannone et al., 2009) but also contributes to the polarity maintenance. $\mathrm{N}$-cadherin inhibition unable the centrosome/Golgi apparatus to enter the swelling and contributes to local defects of Myosin II contraction at the nuclear rear (Luccardini et al., 2013). Cell adhesion molecules play a relevant role for cINs migration as they are at the interface between the extracellular environment and the cytoskeleton.

\section{Migration of cINs: Extracellular Cues Guide cINs Movement}

To allow proper directionality, integration of extracellular signaling is paramount. The extracellular cues are received by exploring the local environment thanks to stochastic branching of the leading process, and relevant cues are transduced at the level of cytoskeleton to grant the proper response of the cell: either extension of a new leading process is the right direction and/or retraction of existing branches (Britto et al., 2009). The first stage in which cINs are challenged by extracellular cues occurs within the GEs. During the differentiation process, newborn cINs need to be displaced from the $\mathrm{VZ}$ and SVZ and be driven toward the exit of the GEs. Two types of signaling drive the movement of cINs away from GEs. One has a chemo-repulsive effect to steer the cells in the good direction and the other stimulates cellular motility to enhance migration.

\section{Chemo-Repulsion within the GEs}

Regarding the mechanisms mediating repulsion of INs from GEs, similarities were found with general mechanisms implicated in axonal guidance. Using a paradigm of in vitro brain slice preparation, Ephrin-A5/EphA4R interaction was shown to be necessary to control the repulsion response of cINs. The guidance molecule Ephrin-A5 is abundant in the VZ and cINs express the Ephrin receptor EphA4 (EphA4R) (Zimmer et al., 2008). In absence of Ephrin-A5, cINs were found ectopically invading the VZ, a phenotype rescued when the slices were treated with recombinant Ephrin-A5 (Zimmer et al., 2008). EphA4R-mediated forward signaling is also used by cINs to avoid migration toward the ventral region of the subpallium (Zimmer et al., 2011) as it also binds Ephrin-B3 present in the MGE and POA. It is noteworthy that EphA4R also promotes cIN migration trough EphrinA2 reverse signaling (Steinecke et al., 2014b). EphA signaling is integrated at the cellular level to remodel the actin cytoskeleton and steer cells in the right direction. Although little is known about the intracellular cascades downstream EphA4 in cINs, it generally acts in neurons through regulation of RhoA to stimulate growth cone collapse (Wahl et al., 2000). Moreover, in cINs, Src family kinases (SFKs) have been implicated in this process. Indeed, SFK inhibition results in the loss of Ephrin-A5/EphA4 repulsion (Zimmer et al., 2008). In mouse, four redundant SFKs have been identified (Thomas and Brugge, 1997) and they have been linked to the phosphorylation of numerous targets. They control the Rho family GTPase (Kullander and Klein, 2002) and inactivate cortactin (Huang et al., 1997; Weaver et al., 2001) resulting in decreased activity of Arp 2/3, actin filament breakdown and growth cone collapse (Weed and Parsons, 2001). Slit/Robo is another signaling pathway mediating chemo-repulsion in GEs and cINs express Roundabout homolog 1 (Robo1) (Bagri et al., 2002; Marillat et al., 2002), a receptor recognizing the ligands Slit homolog 1 and 2 (Slit1 and 2). These ligands and Robo1 are found in a complementary expression pattern in the VZ (Marin et al., 2002), and it was first thought that Robo/Slit signaling was at play to push cINs away from the VZ. However, mice deficient for Slit1/2 do not show cIN migration defects (Marin et al., 2003). Instead, the lack of Slit ligands or removal of Robo1 leads to aberrant striatal invasion by cINs (Andrews et al., 2006; Hernandez-Miranda et al., 2011). This indicates that on the way toward the GEs exit, cINs face a second set of signaling molecules that refine their migratory routes through the LGE, and around the forming striatum. It was previously shown that 
the striatum is a strong repulsive structure for cINs thanks to the expression of class 3 semaphorins: Sema3A and Sema3F (Marin et al., 2001). The effect of semaphorins is mediated in cINs by neuropilin (Nrps) and Plexin receptors. Sema3A transduces signal specifically trough Nrp1 and PlexinA1 receptors (McKinsey et al., 2013) and Robo1 modulate semaphorin-neuropilin/plexin expression levels (Hernandez-Miranda et al., 2011). It is noteworthy that Nrp1 is present exclusively in cINs so that they respond to the repulsive signals secreted by the striatum. Nrp1 expression depends on the transcription factor Sip1 involved in Nkx2-1 down-regulation and Nkx2-1 is a Nrp1 repressor (McKinsey et al., 2013). On the contrary, striatal INs generated by the same progenitors as cINs, do not express Nrp1 as they maintain highs levels of Nkx2.1 (Marin et al., 2000; Butt et al., 2008; NobregaPereira et al., 2008). Since the signaling pathway downstream of Sema3A is highly conserved, although not directly studied in cINs, it is anticipated that similar mechanisms are at play in these cells. Sema3A signaling regulates actin-dependent growth cone collapse trough RhoA, ROCK and LIM Kinase (LIMK) activation to eventually phosphorylate cofilin and inhibits Factin turnover (Aizawa et al., 2001; Causeret et al., 2004). RhoA activation also leads to increased actin contractibility (Zhang et al., 2003). In the axon growth cone, a crosstalk between actin and MT cytoskeletons has been observed as retrograde F-actin flow on filopodia can displace distal position of MTs (Schaefer et al., 2002). Sema3A signaling could also directly regulate MT dynamics by inducing double phosphorylation of Collapsin Response Mediator Protein 2 (CRMP2) by Glycogen Synthase Kinase 3B (GSK3B) and Cyclin-dependent Kinase 5 (CdK5). The double phosphorylated state of CRMP2 reduces its tubulin affinity and overexpression of the phospho- mutant CRMP2 decreases Sema3A-induced growth cone collapse (Uchida et al., 2005).

\section{Migration of cINs: Motogenic Factors}

Newly produced cINs are stimulated by diffusible molecules to enhance movement and migration. A wide range of factors, including neurotrophins and neurotransmitters (NTs), were found to increase cINs motility in vitro (Heng et al., 2007). Demonstration came from experiments in which recombinant Brain Derived Neurotrophic Factor (BDNF) or Neurotrophin4 (NT4) where applied to organotypic slice cultures (Polleux et al., 2002). BDNF- or NT4 effects are mediated by the Tyrosin Kinase B Receptor (TrkBR) (Polleux et al., 2002). Downstream signaling likely involves $\mathrm{PI} 3 \mathrm{~K}$ and the modulation of actin cytoskeleton. However this effect was observed in vitro but not in mouse mutant for TrkB where number and position of cINs are unchanged (Jones et al., 1994; Polleux et al., 2002; SanchezHuertas and Rico, 2011). In vivo, neurotrophin-mediated signaling promoting cINs motility was also linked to the action of Glial Cell-Derived Neurotrophic Factor (GDNF), binding and activating GDNF Family Receptor $\alpha 1$ (GFR $\alpha 1)$. GDNF-mediated effects did not result from expression of Rearranged During Transfection (RET) or Neural Cell Adhesion Molecule (NCAM), two classical co-receptor signaling molecules (Pozas and Ibanez, 2005; Canty et al., 2009). The downstream signaling involves a matrix-bound form of GDNF and syndecan-3. This interaction then activates SFK to promote neurite outgrowth. GDNF may thus promote cell migration by acting on the actin cytoskeleton via SFK and cortactin pathway (Yoneda and Couchman, 2003; Bespalov et al., 2011). Since GFR $\alpha 1$ mutant mice shows perturbations in cINs regionalization and subtype differentiation, GDNF might have additional functions beyond modulating cINs motility (Pozas and Ibanez, 2005; Canty et al., 2009). The hepatocyte growth factor/scatter factor (HGF/SF) and its receptor MET were also reported to have a potent motogenic action on cINs in vitro. Mutant mouse for the urokinase-type plasminogen activator receptor $(U P A R)$ that cleaves and releases the active form of HGF/SF (Powell et al., 2001) or mutant mice for MET (Eagleson et al., 2011) shows a decreased number of cINs in the cortex. The cell-autonomous effect of HGF/SF-mediated signaling was later questioned since MET is not found to be expressed in cINs in vivo but is rather found in projection neurons and their axonal fibers (Eagleson et al., 2011). Several NTs/neuromodulators have also been implicated in cINs migration. Ambient GABA is found in high concentration in the MGE and in the cortical migration streams (Cuzon et al., 2006). cINs express $G_{A B A}$ and $G_{A B A}$ receptors and as a result of an inverted chloride gradient, they respond to GABA by membrane depolarization (Owens et al., 1999) that triggers opening of L-type voltage-sensitive $\mathrm{Ca}^{2+}$ channels and induces $\mathrm{Ca}^{2+}$ transients (Bortone and Polleux, 2009). Antagonizing $\mathrm{GABA}_{\mathrm{A}}$ receptor function prevents cINs from crossing the cortico-striatal barrier, leading to their accumulation at the pallial/subpallial boundary. Conversely, in experiments where exogenous GABA or diazepam are added to brain organotypic slices, a higher number of cINs were found exiting the GEs (Cuzon et al., 2006). Similarly, Glycine $\alpha 2$ receptor is also regulating cIN migration and in particular nucleokinesis by fine tuning acto-myosin II contraction (Avila et al., 2013). Activation of GlyRs by glycine leads to $\mathrm{Ca}^{2+}$ transients due to opening of voltage-gated $\mathrm{Ca}^{2+}$ channels and GlyRs $\alpha 2$ loss of function impairs cINs migration in the cortex. Glutamate signaling through AMPARs, located on the plasma membrane of migrating cINs also induces membrane depolarization and sodium influx (Metin et al., 2000; Manent et al., 2006). Blockade of AMPARs decreases cortical and hippocampal invasion by INs (Manent et al., 2006; Bortone and Polleux, 2009). Membrane depolarization and $\mathrm{Ca}^{2+}$ transients are thought to stimulate cINs motility as calmodulin bound to $\mathrm{Ca}^{2+}$ ions can interact and activate MLCK. In turn, MLCK phosphorylates Myosin Light chain II on serine 19 and promotes acto-myosin contraction (Metin et al., 2000; Bortone and Polleux, 2009). Another example is the motogenic effect mediated by dopamine. Ambient dopamine is secreted in the GEs and close to the lateral VZ by projecting thalamo-striatal axons in the neo-striatum. Dopamine receptors $D_{1}$ and $D_{2}$ are expressed by cINs and have opposite effects on migration (Ohtani et al., 2003). When selectively blocked, $D_{1} R$ induces activation of $D_{2} R$ and impedes migration. This indicates that $D_{1} R$ has migration promoting action and conversely $\mathrm{D}_{2} \mathrm{R}$ is rather a migration stop signal. Other ubiquitous signaling molecules such as adenosine have also been implicated in the modulation of cINs migration. However the underlying mechanisms are still unknown (Silva et al., 2013). 


\section{Migration of cINs: Chemo-Attraction Toward the Cortex}

As cortical INs are steered away from the VZ/SVZ and around the striatum, they are simultaneously attracted toward the cortex by other molecules to cross the cortico-striatal junction and invade the pallium. Neuregulin-1 (Nrg1) is a strong attractant for cINs and can have both short and long-range effects depending on the isoform recruited. CRD-Nrg1, is membrane bound and acts on neighboring cells. It is mainly expressed by LGE cells and contributes to the formation of a permissive migration corridor for cINs. It is sensed by cINs as they probe their environment and inhibition of their branching behavior leads to a decreased ability to follow Nrg-1 gradient (Martini et al., 2009). The downstream signaling involves recruitment and activation of associated tyrosine kinases related to the epidermal growth factor (EGF) receptor ErbB4. Lg-Nrg1 is a diffusible form expressed by the cortex that can act as a long-range attractant to guide cells toward the cortical regions as they exit the LGE. In vivo, the loss of either $\mathrm{Nrg-1}$ or ErbB4 causes migration defects and reduces the number of INs in the cortex (Yau et al., 2003; Flames et al., 2004; Neddens and Buonanno, 2010). At the cellular level, the presence of a Nrg-1 gradient does not prompt cINs to reorient an existing branch but rather to sprout a new leading process in the direction and at an angle corresponding to highest concentration of the attractant. The signaling events downstream ErbB4 have not been completely characterized in cINs, but they seem to be ROCK-independent (Martini et al., 2009). Thanks to its tyrosine kinase activity, ErbB4 can activate several distinct signaling pathways including the ras/raf/MAPK or the PI3 kinase pathway (Scaltriti and Baselga, 2006). In ErbB4 can be cleaved in its intracellular domain and be targeted to the nucleus (Ni et al., 2001). Interestingly, ErbBs can also phosphorylate $\beta$-catenin and modulate Cadherin signaling pathways involved in actin cytoskeleton remodeling (Hazan and Norton, 1998; Behrens, 1999; Al Moustafa et al., 2002). Moreover, other signaling molecules participate to the attraction of cINs toward the cortex. For example, CXCL12 is secreted by proliferating cortical cells from SVZ and $\mathrm{IZ}$ and is an attractant molecule for migrating cINs (Tiveron et al., 2006; Stumm et al., 2007).

\section{Migration of clNs: The Choice of the Migratory Route}

Cortical invasion does not occur in a stochastic manner as cINs integrate and move in migratory streams. At earlier stages of cortical development, two streams can be identified in the pallium: one called intermediate zone (IZ) stream and located above the VZ/SVZ surface (Nadarajah et al., 2002) and the other positioned at the level of the marginal zone (MZ) and called MZ stream (Lavdas et al., 1999). Between E15 and E16, a third subplate (SP) stream forms between the IZ and MZ streams. Other routes have also been identified, for example a caudally directed stream arising from the CGE (Yozu et al., 2005). Although not depending on their birth place (MGE, CGE or POA), the choice of the migratory route by cINs does not seem to be random (Miyoshi and Fishell, 2011). Evidence comes from the observation that populations of cINs migrating along the different cortical streams do not show the same gene expression profile as revealed by microarray analysis on micro-dissected Gad67+ positive cells isolated from either IZ or MZ streams (Antypa et al., 2011). Some population-specific genes, such as Cdh8, Plxnd1, Sema5a, Robo 1 and 2 or the reelin receptor Dab1, play key roles in neuronal migration.

Moreover in vivo experimental approaches have also shed light on intrinsic cellular component that are implicated in cINs sorting between the different migration routes. For example, it was found that mutations in the $R b$ gene unable cINs to enter the MZ stream and redirects them to the IZ stream (Ferguson et al., 2005). This effect is cell autonomous as suggested by cINs transplantation experiments made on wild-type organotypic brain slices. A similar phenotype was found to be linked to glycine receptor $\alpha 2$ subunit (Gly $\alpha 2 \mathrm{R}$ ), present on the plasma membrane of migrating cINs. Activation of Glya2R opens voltage-gated $\mathrm{Ca}^{2+}$ channel (Avila et al., 2013). Extracellular cues seem to indeed play a relevant role in sorting cINs trough the different migration stream. Mutation of both Netrin 1 and $\alpha 3 \beta 1$ integrin, in the cells serving as migration substrate for cINs, gives rise to major migration defects in the MZ stream (Stanco et al., 2009). Finally GABA signaling, in addition to its migration promoting role, seems to be also implicated in the choice of the migratory route during cortical migration. Upon selective blockade of metabotropic $\mathrm{GABA}_{\mathrm{B}} \mathrm{R}, \mathrm{cINs}$ where found to be displaced from the $\mathrm{MZ}$ and $\mathrm{CP}$ stream toward the VZ/SVZ compartments (Lopez-Bendito et al., 2003).

\section{Migration of clNs: Molecular Regulation Controlling the Timing of Cortical Invasion}

In the streams, tangentially migrating cINs do not invade the cortical plate $(\mathrm{CP})$ and this process is coordinated with projection neurons migrating radially to form the cortical layers. Avoidance of the $\mathrm{CP}$ do not require repulsive cues coming from the projection neurons but rather the formation of a permissive corridor in the $\mathrm{MZ}$ and IZ thanks to chemokine signaling. CXCL12 is secreted by proliferating cortical cells from SVZ and IZ and it is a strong attractant molecule for migrating cINs (Daniel et al., 2005; Tiveron et al., 2006; Lopez-Bendito et al., 2008). Two receptors for this chemokine were identified in interneurons, CXCR4 and CXCR7 (Tiveron et al., 2006; Lopez-Bendito et al., 2008; Wang et al., 2011) and they signal through different downstream cascades. CXCR4 signals through $\mathrm{G} \alpha(\mathrm{i} / \mathrm{o})$ while CXCR7 transduces independently on heterodymeric $\mathrm{G}$ proteins (Wang et al., 2011). In immature MGE neurons, CXCR7 acts as potent activator of MAP kinase signaling required for ERK1/2 phosphorylation (Wang et al., 2011). Cxcr7 expression in the cortical plate expression follows a dorsoventral gradient, opposite to Cxcl12 gradient in the SVZ. It was proposed that CXCR7 may lower the concentration of CXCL12 in the CP, generating a gradient from MZ and SVZ to the CP. A gradient of CXCL12 would be important for the regulation of cortical invasion (Wang et al., 2011). Indeed, disruption of CXCR4 or CXCR7 function results in premature exit of cINs from their migratory streams and perturbs their laminar and regional distribution within the neocortex (Li et al., 2008; Lopez-Bendito et al., 2008; Tanaka et al., 2010). 


\section{Integration OF cINs into Cortical Assemblies}

Cortical neurogenesis generates a six-layered cortex and cortical neurons distribute within these layers in an age-dependent manner, deep layers being generated before upper layers. Neurons sharing the same layers exhibit similar patterns of connectivity (Dantzker and Callaway, 2000). The cortex is also organized vertically and cells sharing the same cortical column will be linked by extrinsic connectivity (Mountcastle, 1997). Interneurons have to integrate into cortical circuits in order to fit in these two patterns of organization. Two studies have shown that clonally related cINs are preferentially consigned to specific cortical layers or columns (Brown et al., 2011; Ciceri et al., 2013). cINs generated by clonally-related progenitors are however diverse as they express markers of distinct subtypes. Furthermore, cINs from the same cardinal class are able to form connections with a variety of synaptic partners (Kepecs and Fishell, 2014). From their birthdates, the first interneurons populating the cortex are generated in the MGE and express PV, SST or CR/SST (Butt et al., 2005; Wonders and Anderson, 2006). The second wave of cortical invasion generated by the CGE produces INs expressing VIP, CR/VIP, calbindin (CB) or choline acetyltransferase (ChAT) and NPY, (Yozu et al., 2004; Miyoshi et al., 2010). While pioneer cINs populate the cortex in an inside-out mode following the pattern of cortical integration of projection neurons (Miller, 1985; Fairen et al., 1986; Valcanis and Tan, 2003; Rymar and Sadikot, 2007), late-migrating cINs instead concentrate in supragranular layers, independently of their birthdate (Xu et al., 2004; Rymar and Sadikot, 2007; Miyoshi et al., 2010). Since the birthdate and birthplace are not general predictors of the final specification and lamination of cINs, the mechanisms determining the proper and site-specific integration of INs in the developing cortex need to be clarified. This raises the question whether intrinsic and/or extrinsic factors determine the cortical integration and lamination.

\section{Intrinsic Factors Regulating cINs Integration into Cortical Layers}

There is evidence that a maturational program exists and the behavior of cINs, at a given developmental stage, depends on their cellular age. In the cortical streams, cINs generated at different developmental stages co-exist and they exit the migratory streams at different time points even if the signaling regulating the exit from the streams is the same. Thus, cINs born earlier invade the cortical place before late-born interneurons (Lopez-Bendito et al., 2008). Further evidence supports this concept of intrinsic regulation. For example, it was found that the motility of interneurons in cortical slices gradually decreases as development proceeds and is almost abolished by the end of the first postnatal week (Inamura et al., 2012). Accordingly, lateborn cINs transplanted in younger embryos settle in deep layers instead of occupying the expected superficial layers (Pla et al., 2006). The mechanisms explaining intrinsic regulation of neuronal migration remain elusive. It was suggested that the frequency of $\mathrm{Ca}^{2+}$ transients is reduced as the neuron completes its migratory program (Kumada and Komuro, 2004). Other studies proposed that the intrinsic regulation of motility might be linked to the expression of the potassium-chloride transporter KCC2. KCC2 could modulate cINs motility by reverting the chloride potential and thus reducing membrane depolarization upon $\mathrm{GABA}_{\mathrm{A}}$ receptor activation to serve as a stop signal for migration (Bortone and Polleux, 2009; Inamura et al., 2012). This is in agreement with the observation that cINs up-regulate KCC2 chloride transporter as soon as they exit the tangential mode of migration and start their radial sorting in the cortex (Miyoshi and Fishell, 2011). Cell autonomous regulation also contributes to the survival of interneurons as they invade the cortical plate. Transplantation experiments revealed that many cINs undergo programmed cell death in vivo between postnatal day (P) 7 and P11. When transplanted in older cortices, younger cINs die by apoptosis later than resident cINs (Southwell et al., 2012).

\section{Extrinsic Factors Regulating cINs Integration into Cortical Layers}

Regional distribution of cINs seems also depending on extrinsic signaling. Elegant studies suggested, in the last past years, that molecular cues released by projection neurons contribute to the establishment of the laminar distribution of cINs (Hevner et al., 2004; Pla et al., 2006; Yabut et al., 2007; Lodato et al., 2011b). The works from Hevner (Hevner et al., 2004), Pla (Pla et al., 2006), and Yabut (Yabut et al., 2007) using the reeler mouse model showed that cINs distribution within the cortex mostly results from the aberrant organization of cortical layers rather than the loss of reelin signaling transduction in cINs. The subsequent work from Lodato et al. (2011b) further support this hypothesis. Fezf2 mutant mice lack sub-cerebral projection neurons, while all other projection neurons are normally produced. They show that Fezf2 depletion does not impair cINs specification but rather the lack of subcerebral projection neurons nonautonomously impairs the proper distribution of SST, PV but not CR cINs subtype. Delayed overexpression of Fezf2 in Fezf2 null mice leads to the production of ectopically located clusters of subcerebral projection neurons. Many cINs invade these aggregates while the number of INs recruited depends on the size of the ectopic aggregates. Local excitatory and inhibitory signals may also influence the final positioning of INs (De Marco Garcia et al., 2011; Lyons et al., 2012; McKinsey et al., 2013). For example, it was shown that attenuating the activity of specific cIN populations affects the migration and morphologic development of cIN (De Marco Garcia et al., 2011). A number of activity-dependent genes specifically expressed by cINs have been identified. These include Dlx1, Elmo1, and Mef2c. Moreover the observation that voltage-gated $\mathrm{Ca}^{2+}$ influx may induce de novo gene expression opens the possibility that local activity might regulate direct region-specific differentiation and maturation of INs (De Marco Garcia et al., 2011; West and Greenberg, 2011). Additional evidence came from studies showing that MGE-derived interneurons are able to integrate in pathological neural circuits (Martinez-Cerdeno et al., 2010; Braz et al., 2012). 


\section{Conclusion}

The recognition that many neurologic disorders such as schizophrenia, epilepsy and autism have components related to cIN development greatly prompted advances in this field. Postmortem analysis of the human brain and studies performed in primates strongly support the idea that human and primate cINs are produced in both dorsal and ventral regions (Fertuzinhos et al., 2009; Hansen et al., 2013; Ma et al., 2013). These studies have been instrumental to highlight the differences and similarities between in cINs generation across species, acknowledging more similarities than initially expected. These findings have given more credit to studies performed in rodents, designed to understand the genetic and molecular regulation underlying human pathology. For example, in the case of schizophrenia, NRG1 and ERB4 as well as DISC1 have been identified as susceptibility genes in human (Millar et al., 2000a,b; Corvin et al., 2004; Marin, 2012). Studies performed in rodents established a coherent outline of the biological causes of this human disease (Flames et al., 2004; Fazzari et al., 2010). How developmental perturbations of cINs lead to a specific brain disorder remains unclear although it has been proposed to depend, to some extent, on the cIN subtype affected (Marin, 2012). Thus, understanding the role of different classes of cINs and the neuro-circuitry they modulate will be relevant for unraveling the genetic causes of human diseases and to propose effective therapeutic approaches.

In the last decades, important advancements were made in the understanding of how INs are generated and function into networks. However, the fine regulation of cIN development might not be explained merely by genetic programs and extracellular signaling. Indeed, a fully new dimension of regulation, including post-transcriptional and post-translational modifications (PTMs) might be at play during corticogenesis. Post-transcriptional and PTMs can oppose or reinforce genetically-encoded and/or extrinsically-mediated signaling. A recent study explored the role of miRNA in distinct aspects of cINs development (Tuncdemir et al., 2014). In this study, Dicer, an enzyme required for miRNA processing and maturation was genetically deleted from MGE-derived cINs. Interestingly, the loss of miRNAs had no effect on cell proliferation and initiation of tangential migration but affected the transition from tangential to radial migration as well as modified the survival and maturation of cINs. Upon Dicer knockdown there was a precocious expression of cINs markers such as SST, GAD65 and NPY and at a later stage. MGE-derived cells failed to express markers of their subtype identity. PV-expressing cINs seem particularly affected by the absence of miRNAs. Furthermore, a different

\section{References}

Aizawa, H., Wakatsuki, S., Ishii, A., Moriyama, K., Sasaki, Y., Ohashi, K., et al. (2001). Phosphorylation of cofilin by LIM-kinase is necessary for semaphorin 3A-induced growth cone collapse. Nat. Neurosci. 4, 367-373. doi: $10.1038 / 86011$

Al Moustafa, A. E., Yen, L., Benlimame, N., and Alaoui-Jamali, M. A. (2002). Regulation of E-cadherin/catenin complex patterns by epidermal growth factor profile of gene expression related to differentiation, cellular interaction and survival was found in Dicer knockout mice. The role of miRNA signaling was also recently tested in a mouse model of schizophrenia and bipolar disorder (Toritsuka et al., 2013). This study showed a direct link between the 22q11 micro deletion and defects in cortical and hippocampal interneuron migration, relying on functional abnormalities in CXCR4/CXCL12 signaling. Mechanistically, Toritsuka et al. (2013) demonstrate the pivotal role of DiGeorge syndrome critical region gene 8 (Dgcr8)mediated in miR-200a regulation necessary for the maintenance of CXCR4 levels. PTMs occur in most proteins and often contribute to their functions and subcellular behaviors. Not many studies were developed to investigate the contribution of PTMs on brain development but there is evidence that they can regulate different aspects of cIN development. For example, it was demonstrated that acylation of $\mathrm{SHH} \mathrm{N}$-terminus changes its efficacy as a signaling molecule and greatly enhances its ability to ventralize early LGE progenitors (Kohtz et al., 2001). A C-terminal cholesterol modification has also been identified on $\mathrm{SHH}$ relevant for $\mathrm{SHH}$ tethering to the cell surface (Porter et al., 1996). At the functional level, these PTMs were showed to be primordial in determining $\mathrm{SHH}$ "short range" or "long range" function (Burke et al., 1999). Another example is the polysialylation of the neural cell adhesion molecule (PSA-NCAM), important to control the timing of the perisomatic GABAergic synapse maturation in the mouse cortex (Di Cristo et al., 2007). Di Cristo and colleagues showed that premature removal of PSA in the visual cortex resulted in precocious maturation of perisomatic innervation by $\mathrm{PV}$ basket cINs. Interestingly, polysialytransferases have been implicated in schizophrenia (Arai et al., 2006; Tao et al., 2007; Isomura et al., 2011). In light of this, it seems highly pertinent to pursue on understanding how genes, signaling molecules and environment communicate to shape brain development and function.

\section{Acknowledgments}

LN is a Research Associate and CG a postdoctoral fellow at the Belgian National Fund for Scientific Research (F.R.S-F.N.R.S.). $\mathrm{EP}$ is a postdoctoral fellow. $\mathrm{LN}$ is funded by grants from the F.R.S.-F.N.R.S., the Fonds Léon Fredericq, the Fondation Médicale Reine Elisabeth, and the Belgian Science Policy (IAP-VII network P7/20). LN and EP are funded by a grant from Actions de Recherche Concertée (ARC11/16-01). Some scientific projects in the Nguyen are funded by the Walloon excellence in lifesciences and biotechnology (WELBIO). receptor modulation in human lung cancer cells. Lung Cancer 37, 49-56. doi: 10.1016/S0169-5002(02)00025-9

Amano, M., Ito, M., Kimura, K., Fukata, Y., Chihara, K., Nakano, T., et al. (1996). Phosphorylation and activation of myosin by Rho-associated kinase (Rho-kinase). J. Biol. Chem. 271, 20246-20249.

Anderson, S. A., Eisenstat, D. D., Shi, L., and Rubenstein, J. L. (1997). Interneuron migration from basal forebrain to neocortex: dependence on Dlx genes. Science $278,474-476$. 
Andrews, W., Liapi, A., Plachez, C., Camurri, L., Zhang, J., Mori, S., et al. (2006). Robol regulates the development of major axon tracts and interneuron migration in the forebrain. Development 133, 2243-2252. doi: 10.1242/dev.02379

Antypa, M., Faux, C., Eichele, G., Parnavelas, J. G., and Andrews, W. D. (2011). Differential gene expression in migratory streams of cortical interneurons. Eur. J. Neurosci. 34, 1584-1594. doi: 10.1111/j.1460-9568.2011.07896.x

Aoto, K., Nishimura, T., Eto, K., and Motoyama, J. (2002). Mouse GLI3 regulates Fgf8 expression and apoptosis in the developing neural tube, face, and limb bud. Dev. Biol. 251, 320-332. doi: 10.1006/dbio.2002.0811

Arai, M., Yamada, K., Toyota, T., Obata, N., Haga, S., Yoshida, Y., et al. (2006). Association between polymorphisms in the promoter region of the sialyltransferase 8B (SIAT8B) gene and schizophrenia. Biol. Psychiatry 59, 652-659. doi: 10.1016/j.biopsych.2005.08.016

Avila, A., Vidal, P. M., Dear, T. N., Harvey, R. J., Rigo, J. M., and Nguyen, L. (2013). Glycine receptor alpha2 subunit activation promotes cortical interneuron migration. Cell Rep. 4, 738-750. doi: 10.1016/j.celrep.2013.07.016

Azim, E., Jabaudon, D., Fame, R. M., and Macklis, J. D. (2009). SOX6 controls dorsal progenitor identity and interneuron diversity during neocortical development. Nat. Neurosci. 12, 1238-1247. doi: 10.1038/nn.2387

Bagri, A., Marin, O., Plump, A. S., Mak, J., Pleasure, S. J., Rubenstein, J. L., et al. (2002). Slit proteins prevent midline crossing and determine the dorsoventral position of major axonal pathways in the mammalian forebrain. Neuron 33, 233-248. doi: 10.1016/S0896-6273(02)00561-5

Bai, C. B., Stephen, D., and Joyner, A. L. (2004). All mouse ventral spinal cord patterning by hedgehog is Gli dependent and involves an activator function of Gli3. Dev. Cell 6, 103-115. doi: 10.1016/S1534-5807(03)00394-0

Batista-Brito, R., Rossignol, E., Hjerling-Leffler, J., Denaxa, M., Wegner, M., Lefebvre, V., et al. (2009). The cell-intrinsic requirement of Sox6 for cortical interneuron development. Neuron 63, 466-481. doi: 10.1016/j.neuron.2009.08.005

Baudoin, J. P., Alvarez, C., Gaspar, P., and Metin, C. (2008). Nocodazole-induced changes in microtubule dynamics impair the morphology and directionality of migrating medial ganglionic eminence cells. Dev. Neurosci. 30, 132-143. doi: 10.1159/000109858

Baudoin, J. P., Viou, L., Launay, P. S., Luccardini, C., Espeso Gil, S., Kiyasova, V., et al. (2012). Tangentially migrating neurons assemble a primary cilium that promotes their reorientation to the cortical plate. Neuron $76,1108-1122$. doi: 10.1016/j.neuron.2012.10.027

Behrens, J. (1999). Cadherins and catenins: role in signal transduction and tumor progression. Cancer Metastasis Rev. 18, 15-30.

Bellion, A., and Metin, C. (2005). Early regionalisation of the neocortex and the medial ganglionic eminence. Brain Res. Bull. 66, 402-409. doi: 10.1016/j.brainresbull.2005.07.010

Bellion, A., Baudoin, J. P., Alvarez, C., Bornens, M., and Metin, C. (2005). Nucleokinesis in tangentially migrating neurons comprises two alternating phases: forward migration of the Golgi/centrosome associated with centrosome splitting and myosin contraction at the rear. J. Neurosci. 25, 5691-5699. doi: 10.1523/JNEUROSCI.1030-05.2005

Bespalov, M. M., Sidorova, Y. A., Tumova, S., Ahonen-Bishopp, A., Magalhaes, A. C., Kulesskiy, E., et al. (2011). Heparan sulfate proteoglycan syndecan-3 is a novel receptor for GDNF, neurturin, and artemin. J. Cell Biol. 192, 153-169. doi: $10.1083 /$ jcb.201009136

Besson, A., Gurian-West, M., Schmidt, A., Hall, A., and Roberts, J. M. (2004). p27Kip1 modulates cell migration through the regulation of RhoA activation. Genes Dev. 18, 862-876. doi: 10.1101/gad.1185504

Blaess, S., Corrales, J. D., and Joyner, A. L. (2006). Sonic hedgehog regulates Gli activator and repressor functions with spatial and temporal precision in the $\mathrm{mid} /$ hindbrain region. Development 133, 1799-1809. doi: 10.1242/dev.02339

Borello, U., Cobos, I., Long, J. E., McWhirter, J. R., Murre, C., and Rubenstein, J. L. (2008). FGF15 promotes neurogenesis and opposes FGF8 function during neocortical development. Neural Dev. 3:17. doi: 10.1186/1749-8104-3-17

Bortone, D., and Polleux, F. (2009). KCC2 expression promotes the termination of cortical interneuron migration in a voltage-sensitive calcium-dependent manner. Neuron 62, 53-71. doi: 10.1016/j.neuron.2009.01.034

Braz, J. M., Sharif-Naeini, R., Vogt, D., Kriegstein, A., Alvarez-Buylla, A., Rubenstein, J. L., et al. (2012). Forebrain GABAergic neuron precursors integrate into adult spinal cord and reduce injury-induced neuropathic pain. Neuron 74 , 663-675. doi: 10.1016/j.neuron.2012.02.033
Briscoe, J., and Ericson, J. (2001). Specification of neuronal fates in the ventral neural tube. Curr. Opin. Neurobiol. 11, 43-49. doi: 10.1016/S0959-4388(00)00172-0

Britto, J. M., Johnston, L. A., and Tan, S. S. (2009). The stochastic search dynamics of interneuron migration. Biophys. J. 97, 699-709. doi: 10.1016/j.bpj.2009.04.064

Brown, K. N., Chen, S., Han, Z., Lu, C. H., Tan, X., Zhang, X. J., et al. (2011). Clonal production and organization of inhibitory interneurons in the neocortex. Science 334, 480-486. doi: 10.1126/science.1208884

Burke, R., Nellen, D., Bellotto, M., Hafen, E., Senti, K. A., Dickson, B. J., et al. (1999). Dispatched, a novel sterol-sensing domain protein dedicated to the release of cholesterol-modified hedgehog from signaling cells. Cell 99, 803-815.

Butt, S. J., Fuccillo, M., Nery, S., Noctor, S., Kriegstein, A., Corbin, J. G., et al. (2005). The temporal and spatial origins of cortical interneurons predict their physiological subtype. Neuron 48, 591-604. doi: 10.1016/j.neuron.2005.09.034

Butt, S. J., Sousa, V. H., Fuccillo, M. V., Hjerling-Leffler, J., Miyoshi, G., Kimura, S., et al. (2008). The requirement of $\mathrm{Nkx2-1}$ in the temporal specification of cortical interneuron subtypes. Neuron 59, 722-732. doi: 10.1016/j.neuron.2008.07.031

Cai, Y., Zhang, Q., Wang, C., Zhang, Y., Ma, T., Zhou, X., et al. (2013). Nuclear receptor COUP-TFII-expressing neocortical interneurons are derived from the medial and lateral/caudal ganglionic eminence and define specific subsets of mature interneurons. J. Comp. Neurol. 521, 479-497. doi: 10.10 $02 /$ cne. 23186

Cameron, H. A., Hazel, T. G., and McKay, R. D. (1998). Regulation of neurogenesis by growth factors and neurotransmitters. J. Neurobiol. 36, 287-306.

Canty, A. J., Dietze, J., Harvey, M., Enomoto, H., Milbrandt, J., and Ibanez, C. F. (2009). Regionalized loss of parvalbumin interneurons in the cerebral cortex of mice with deficits in GFRalphal signaling. J. Neurosci. 29, 10695-10705. doi: 10.1523/JNEUROSCI.2658-09.2009

Casarosa, S., Fode, C., and Guillemot, F. (1999). Mash1 regulates neurogenesis in the ventral telencephalon. Development 126, 525-534.

Causeret, F., Hidalgo-Sanchez, M., Fort, P., Backer, S., Popoff, M. R., GauthierRouviere, C., et al. (2004). Distinct roles of Rac1/Cdc42 and Rho/Rock for axon outgrowth and nucleokinesis of precerebellar neurons toward netrin 1 . Development 131, 2841-2852. doi: 10.1242/dev.01162

Chai, X., Forster, E., Zhao, S., Bock, H. H., and Frotscher, M. (2009a). Reelin acts as a stop signal for radially migrating neurons by inducing phosphorylation of $\mathrm{n}$-cofilin at the leading edge. Commun. Integr. Biol. 2, 375-377. doi: 10.4161/cib.2.4.8614

Chai, X., Forster, E., Zhao, S., Bock, H. H., and Frotscher, M. (2009b). Reelin stabilizes the actin cytoskeleton of neuronal processes by inducing $\mathrm{n}$-cofilin phosphorylation at serine3. J. Neurosci. 29, 288-299. doi: 10.1523/JNEUROSCI.2934-08.2009

Chrzanowska-Wodnicka, M., and Burridge, K. (1996). Rho-stimulated contractility drives the formation of stress fibers and focal adhesions. J. Cell Biol. 133, 1403-1415.

Ciceri, G., Dehorter, N., Sols, I., Huang, Z. J., Maravall, M., and Marin, O. (2013). Lineage-specific laminar organization of cortical GABAergic interneurons. Nat. Neurosci. 16, 1199-1210. doi: 10.1038/nn.3485

Cobos, I., Calcagnotto, M. E., Vilaythong, A. J., Thwin, M. T., Noebels, J. L., Baraban, S. C., et al. (2005). Mice lacking Dlx1 show subtype-specific loss of interneurons, reduced inhibition and epilepsy. Nat. Neurosci. 8, 1059-1068. doi: $10.1038 / \mathrm{nn} 1499$

Colombo, E., Collombat, P., Colasante, G., Bianchi, M., Long, J., Mansouri, A., et al. (2007). Inactivation of Arx, the murine ortholog of the X-linked lissencephaly with ambiguous genitalia gene, leads to severe disorganization of the ventral telencephalon with impaired neuronal migration and differentiation. J. Neurosci. 27, 4786-4798. doi: 10.1523/JNEUROSCI.0417-07.2007

Corvin, A., Nangle, J. M., and Gill, M. (2004). Schizophrenia susceptibility genes: recent discoveries and new challenges. Ir. Med. J. 97, 70-72.

Cuzon, V. C., Yeh, P. W., Cheng, Q., and Yeh, H. H. (2006). Ambient GABA promotes cortical entry of tangentially migrating cells derived from the medial ganglionic eminence. Cereb. Cortex 16, 1377-1388. doi: 10.1093/cercor/bhj084

Daniel, D., Rossel, M., Seki, T., and Konig, N. (2005). Stromal cell-derived factor-1 (SDF-1) expression in embryonic mouse cerebral cortex starts in the intermediate zone close to the pallial-subpallial boundary and extends progressively towards the cortical hem. Gene Expr. Patterns 5, 317-322. doi: 10.1016/j.modgep.2004.10.007 
Dantzker, J. L., and Callaway, E. M. (2000). Laminar sources of synaptic input to cortical inhibitory interneurons and pyramidal neurons. Nat. Neurosci. 3, 701-707. doi: 10.1038/76656

De Marco Garcia, N. V., Karayannis, T., and Fishell, G. (2011). Neuronal activity is required for the development of specific cortical interneuron subtypes. Nature 472, 351-355. doi: 10.1038/nature09865

Denaxa, M., Chan, C. H., Schachner, M., Parnavelas, J. G., and Karagogeos, D. (2001). The adhesion molecule TAG-1 mediates the migration of cortical interneurons from the ganglionic eminence along the corticofugal fiber system. Development 128, 4635-4644.

Denaxa, M., Kyriakopoulou, K., Theodorakis, K., Trichas, G., Vidaki, M., Takeda, Y., et al. (2005). The adhesion molecule TAG-1 is required for proper migration of the superficial migratory stream in the medulla but not of cortical interneurons. Dev. Biol. 288, 87-99. doi: 10.1016/j.ydbio.2005.09.021

Di Cristo, G., Chattopadhyaya, B., Kuhlman, S. J., Fu, Y., Belanger, M. C., Wu, C. Z., et al. (2007). Activity-dependent PSA expression regulates inhibitory maturation and onset of critical period plasticity. Nat. Neurosci. 10, 1569-1577. doi: $10.1038 / \mathrm{nn} 2008$

Dobbertin, A., Gervais, A., Glowinski, J., and Mallat, M., (2000). Activation of ionotropic glutamate receptors reduces the production of transforming growth factor-beta2 by developing neurons. Eur. J. Neurosci. 12, 4589-4593. doi: 10.1046/j.0953-816X.2000.01354.x

Eagleson, K. L., Campbell, D. B., Thompson, B. L., Bergman, M. Y., and Levitt, P. (2011). The autism risk genes MET and PLAUR differentially impact cortical development. Autism Res. 4, 68-83. doi: 10.1002/aur.172

Echelard, Y., Epstein, D. J., St-Jacques, B., Shen, L., Mohler, J., McMahon, J. A., et al. (1993). Sonic hedgehog, a member of a family of putative signaling molecules, is implicated in the regulation of CNS polarity. Cell 75, 1417-1430.

Eisenstat, D. D., Liu, J. K., Mione, M., Zhong, W., Yu, G., Anderson, S. A., et al. (1999). DLX-1, DLX-2, and DLX-5 expression define distinct stages of basal forebrain differentiation. J. Comp. Neurol. 414, 217-237.

Fairen, A., Cobas, A., and Fonseca, M. (1986). Times of generation of glutamic acid decarboxylase immunoreactive neurons in mouse somatosensory cortex. J. Comp. Neurol. 251, 67-83. doi: 10.1002/cne.902510105

Fazzari, P., Paternain, A. V., Valiente, M., Pla, R., Lujan, R., Lloyd, K., et al. (2010). Control of cortical GABA circuitry development by Nrg1 and ErbB4 signalling. Nature 464, 1376-1380. doi: 10.1038/nature08928

Ferguson, K. L., McClellan, K. A., Vanderluit, J. L., McIntosh, W. C., Schuurmans, C., Polleux, F., et al. (2005). A cell-autonomous requirement for the cell cycle regulatory protein, $\mathrm{Rb}$, in neuronal migration. EMBO J. 24, 4381-4391. doi: 10.1038/sj.emboj.7600887

Fertuzinhos, S., Krsnik, Z., Kawasawa, Y. I., Rasin, M. R., Kwan, K. Y., Chen, J. G., et al. (2009). Selective depletion of molecularly defined cortical interneurons in human holoprosencephaly with severe striatal hypoplasia. Cereb. Cortex 19, 2196-2207. doi: 10.1093/cercor/bhp009

Flames, N., Long, J. E., Garratt, A. N., Fischer, T. M., Gassmann, M., Birchmeier, C., et al. (2004). Short- and long-range attraction of cortical GABAergic interneurons by neuregulin-1. Neuron 44, 251-261. doi: 10.1016/j.neuron.2004.09.028

Flames, N., Pla, R., Gelman, D. M., Rubenstein, J. L., Puelles, L., and Marin, O. (2007). Delineation of multiple subpallial progenitor domains by the combinatorial expression of transcriptional codes. J. Neurosci. 27, 9682-9695. doi: 10.1523/JNEUROSCI.2750-07.2007

Flandin, P., Zhao, Y., Vogt, D., Jeong, J., Long, J., Potter, G., et al. (2011). Lhx6 and Lhx8 coordinately induce neuronal expression of Shh that controls the generation of interneuron progenitors. Neuron 70, 939-950. doi: 10.1016/j.neuron.2011.04.020

Fode, C., Ma, Q., Casarosa, S., Ang, S. L., Anderson, D. J., and Guillemot, F. (2000). A role for neural determination genes in specifying the dorsoventral identity of telencephalic neurons. Genes Dev. 14, 67-80. doi: 10.1101/gad.14.1.67

Fogarty, M., Grist, M., Gelman, D., Marin, O., Pachnis, V., and Kessaris, N. (2007). Spatial genetic patterning of the embryonic neuroepithelium generates GABAergic interneuron diversity in the adult cortex. J. Neurosci. 27, 10935-10946. doi: 10.1523/JNEUROSCI.1629-07.2007

Fragkouli, A., Hearn, C., Errington, M., Cooke, S., Grigoriou, M., and Bliss, T. (2005). Loss of forebrain cholinergic neurons and impairment in spatial learning and memory in LHX7-deficient mice. Eur. J. Neurosci. 21, 2923-2938. doi: 10.1111/j.1460-9568.2005.04141.x

Franco, S. J., and Huttenlocher, A. (2005). Regulating cell migration: calpains make the cut. J. Cell Sci. 118, 3829-3838. doi: 10.1242/jcs.02562
Friocourt, G., Liu, J. S., Antypa, M., Rakic, S., Walsh, C. A., and Parnavelas, J. G. (2007). Both doublecortin and doublecortin-like kinase play a role in cortical interneuron migration. J. Neurosci. 27, 3875-3883. doi: 10.1523/JNEUROSCI.4530-06.2007

Fuccillo, M., Rallu, M., McMahon, A. P., and Fishell, G. (2004). Temporal requirement for hedgehog signaling in ventral telencephalic patterning. Development 131, 5031-5040. doi: 10.1242/dev.01349

Gallagher, P. J., Herring, B. P., and Stull, J. T. (1997). Myosin light chain kinases. J. Muscle Res. Cell Motil. 18, 1-16.

Gelman, D. M., and Marin, O. (2010). Generation of interneuron diversity in the mouse cerebral cortex. Eur. J. Neurosci. 31, 2136-2141. doi: 10.1111/j.14609568.2010.07267.x

Gelman, D. M., Martini, F. J., Nobrega-Pereira, S., Pierani, A., Kessaris, N., and Marin, O. (2009). The embryonic preoptic area is a novel source of cortical GABAergic interneurons. J. Neurosci. 29, 9380-9389. doi: 10.1523/JNEUROSCI.0604-09.2009

Gelman, D., Griveau, A., Dehorter, N., Teissier, A., Varela, C., Pla, R., et al. (2011). A wide diversity of cortical GABAergic interneurons derives from the embryonic preoptic area. J. Neurosci. 31, 16570-16580. doi: 10.1523/JNEUROSCI.4068-11.2011

Giannone, G., Mege, R. M., and Thoumine, O. (2009). Multi-level molecular clutches in motile cell processes. Trends Cell Biol. 19, 475-486. doi: 10.1016/j.tcb.2009.07.001

Glickstein, S. B., Alexander, S., and Ross, M. E. (2007a). Differences in cyclin D2 and D1 protein expression distinguish forebrain progenitor subsets. Cereb. Cortex 17, 632-642. doi: 10.1093/cercor/bhk008

Glickstein, S. B., Moore, H., Slowinska, B., Racchumi, J., Suh, M., Chuhma, N., et al. (2007b). Selective cortical interneuron and GABA deficits in cyclin D2-null mice. Development 134, 4083-4093. doi: 10.1242/dev.008524

Glickstein, S. B., Monaghan, J. A., Koeller, H. B., Jones, T. K., and Ross, M. E. (2009). Cyclin D2 is critical for intermediate progenitor cell proliferation in the embryonic cortex. J. Neurosci. 29, 9614-9624. doi: 10.1523/JNEUROSCI.228409.2009

Godin, J. D., Thomas, N., Laguesse, S., Malinouskaya, L., Close, P., Malaise, O., et al. (2012). p27(Kip1) is a microtubule-associated protein that promotes microtubule polymerization during neuron migration. Dev. Cell 23, 729-744. doi: 10.1016/j.devcel.2012.08.006

Gopal, P. P., Simonet, J. C., Shapiro, W., and Golden, J. A. (2010). Leading process branch instability in Lis $1+/$ - nonradially migrating interneurons. Cereb. Cortex 20, 1497-1505. doi: 10.1093/cercor/bhp211

Govek, E. E., Hatten, M. E., and Van Aelst, L. (2011). The role of Rho GTPase proteins in CNS neuronal migration. Dev. Neurobiol. 71, 528-553. doi: 10.1002/dneu.20850

Gutin, G., Fernandes, M., Palazzolo, L., Paek, H., Yu, K., Ornitz, D. M., et al. (2006). FGF signalling generates ventral telencephalic cells independently of SHH. Development 133, 2937-2946. doi: 10.1242/dev.02465

Hansen, D. V., Lui, J. H., Flandin, P., Yoshikawa, K., Rubenstein, J. L., AlvarezBuylla, A., et al. (2013). Non-epithelial stem cells and cortical interneuron production in the human ganglionic eminences. Nat. Neurosci. 16, 1576-1587. doi: 10.1038/nn.3541

Haydar, T. F., Wang, F., Schwartz, M. L., and Rakic, P. (2000). Differential modulation of proliferation in the neocortical ventricular and subventricular zones. J. Neurosci. 20, 5764-5774.

Hazan, R. B., and Norton, L. (1998). The epidermal growth factor receptor modulates the interaction of E-cadherin with the actin cytoskeleton. J. Biol. Chem. 273, 9078-9084.

He, M., Zhang, Z. H., Guan, C. B., Xia, D., and Yuan, X. B. (2010). Leading tip drives soma translocation via forward F-actin flow during neuronal migration. J. Neurosci. 30, 10885-10898. doi: 10.1523/JNEUROSCI.0240-10.2010

Heasman, S. J., and Ridley, A. J. (2008). Mammalian Rho GTPases: new insights into their functions from in vivo studies. Nat. Rev. Mol. Cell Biol. 9, 690-701. doi: $10.1038 / \mathrm{nrm} 2476$

Hebert, J. M., and Fishell, G. (2008). The genetics of early telencephalon patterning: some assembly required. Nat. Rev. Neurosci. 9, 678-685. doi: 10.1038/nrn2463

Heng, J. I., Moonen, G., and Nguyen, L. (2007). Neurotransmitters regulate cell migration in the telencephalon. Eur. J. Neurosci. 26, 537-546. doi: 10.1111/j.1460-9568.2007.05694.x

Hernandez-Miranda, L. R., Cariboni, A., Faux, C., Ruhrberg, C., Cho, J. H., Cloutier, J. F., et al. (2011). Robol regulates semaphorin signaling to guide the 
migration of cortical interneurons through the ventral forebrain. J. Neurosci. 31, 6174-6187. doi: 10.1523/JNEUROSCI.5464-10.2011

Hevner, R. F., Daza, R. A., Englund, C., Kohtz, J., and Fink, A. (2004). Postnatal shifts of interneuron position in the neocortex of normal and reeler mice: evidence for inward radial migration. Neuroscience 124, 605-618. doi: 10.1016/j.neuroscience.2003.11.033

Higashida, C., Miyoshi, T., Fujita, A., Oceguera-Yanez, F., Monypenny, J., Andou, Y., et al. (2004). Actin polymerization-driven molecular movement of mDial in living cells. Science 303, 2007-2010. doi: 10.1126/science.1093923

Higginbotham, H. R., and Gleeson, J. G. (2007). The centrosome in neuronal development. Trends Neurosci. 30, 276-283. doi: 10.1016/j.tins.2007.04.001

Horton, S., Meredith, A., Richardson, J. A., and Johnson, J. E. (1999). Correct coordination of neuronal differentiation events in ventral forebrain requires the bHLH factor MASH1. Mol. Cell. Neurosci. 14, 355-369. doi: 10.1006/mcne.1999.0791

Huang, C., Ni, Y., Wang, T., Gao, Y., Haudenschild, C. C., and Zhan, X. (1997). Down-regulation of the filamentous actin cross-linking activity of cortactin by Src-mediated tyrosine phosphorylation. J. Biol. Chem. 272, 13911-13915.

Inamura, N., Kimura, T., Tada, S., Kurahashi, T., Yanagida, M., Yanagawa, Y., et al. (2012). Intrinsic and extrinsic mechanisms control the termination of cortical interneuron migration. J. Neurosci. 32, 6032-6042. doi: 10.1523/JNEUROSCI.3446-11.2012

Ingham, P. W., and McMahon, A. (2001). P. Hedgehog signaling in animal development: paradigms and principles. Genes Dev. 15, 3059-3087. doi: $10.1101 /$ gad.938601

Ishizaki, T., Naito, M., Fujisawa, K., Maekawa, M., Watanabe, N., Saito, Y., et al. (1997). p160ROCK, a Rho-associated coiled-coil forming protein kinase, works downstream of Rho and induces focal adhesions. FEBS Lett. 404, 118-124.

Isomura, R., Kitajima, K., and Sato, C. (2011). Structural and functional impairments of polysialic acid by a mutated polysialyltransferase found in schizophrenia. J. Biol. Chem. 286, 21535-21545. doi: 10.1074/jbc.M111.221143

Jessell, T. M. (2000). Neuronal specification in the spinal cord: inductive signals and transcriptional codes. Nat. Rev. Genet. 1, 20-29. doi: 10.1038/35049541

Jones, K. R., Farinas, I., Backus, C., and Reichardt, L. F. (1994). Targeted disruption of the BDNF gene perturbs brain and sensory neuron development but not motor neuron development. Cell 76, 989-999.

Kappeler, C., Saillour, Y., Baudoin, J. P., Tuy, F. P., Alvarez, C., Houbron, C., et al. (2006). Branching and nucleokinesis defects in migrating interneurons derived from doublecortin knockout mice. Hum. Mol. Genet. 15, 1387-1400. doi: $10.1093 / \mathrm{hmg} / \mathrm{ddl} 062$

Kawauchi, T., Chihama, K., Nabeshima, Y., and Hoshino, M. (2006). Cdk5 phosphorylates and stabilizes p27kip1 contributing to actin organization and cortical neuronal migration. Nat. Cell Biol. 8, 17-26. doi: 10.1038/ncb1338

Kenney, A. M., and Rowitch, D. H. (2000). Sonic hedgehog promotes G(1) cyclin expression and sustained cell cycle progression in mammalian neuronal precursors. Mol. Cell. Biol. 20, 9055-9067. doi: 10.1128/MCB.20.23.9055-9067.2000

Kenney, A. M., Cole, M. D., and Rowitch, D. H. (2003). Nmyc upregulation by sonic hedgehog signaling promotes proliferation in developing cerebellar granule neuron precursors. Development 130, 15-28. doi: 10.1242/dev.00182

Kenney, A. M., Widlund, H. R., and Rowitch, D. H. (2004). Hedgehog and PI-3 kinase signaling converge on Nmyc1 to promote cell cycle progression in cerebellar neuronal precursors. Development 131, 217-228. doi: 10.1242/dev.00891

Kepecs, A., and Fishell, G. (2014). Interneuron cell types are fit to function. Nature 505, 318-326. doi: 10.1038/nature12983

Kimura, K., Ito, M., Amano, M., Chihara, K., Fukata, Y., Nakafuku, M., et al. (1996). Regulation of myosin phosphatase by Rho and Rho-associated kinase (Rho-kinase). Science 273, 245-248.

Kohtz, J. D., Lee, H. Y., Gaiano, N., Segal, J., Ng, E., Larson, T., et al. (2001). Nterminal fatty-acylation of sonic hedgehog enhances the induction of rodent ventral forebrain neurons. Development 128, 2351-2363.

Kullander, K., and Klein, R. (2002). Mechanisms and functions of Eph and ephrin signalling. Nat. Rev. Mol. Cell Biol. 3, 475-486. doi: 10.1038/nrm856

Kumada, T., and Komuro, H. (2004). Completion of neuronal migration regulated by loss of $\mathrm{Ca}(2+)$ transients. Proc. Natl. Acad. Sci. U.S.A. 101, 8479-8484. doi: 10.1073/pnas.0401000101

Kuschel, S., Ruther, U., and Theil, T. (2003). A disrupted balance between $\mathrm{Bmp} / \mathrm{Wnt}$ and Fgf signaling underlies the ventralization of the Gli3 mutant telencephalon. Dev. Biol. 260, 484-495. doi: 10.1016/S0012-1606(03)00252-5
Laurie, D. J., Wisden, W., and Seeburg, P. H. (1992). The distribution of thirteen GABAA receptor subunit mRNAs in the rat brain. III. Embryonic and postnatal development. J. Neurosci. 12, 4151-4172.

Lavdas, A. A., Grigoriou, M., Pachnis, V., and Parnavelas, J. G. (1999). The medial ganglionic eminence gives rise to a population of early neurons in the developing cerebral cortex. J. Neurosci. 19, 7881-7888.

Li, G., Adesnik, H., Li, J., Long, J., Nicoll, R. A., Rubenstein, J. L., et al. (2008). Regional distribution of cortical interneurons and development of inhibitory tone are regulated by Cxcl12/Cxcr4 signaling. J. Neurosci. 28, 1085-1098. doi: 10.1523/JNEUROSCI.4602-07.2008

Liodis, P., Denaxa, M., Grigoriou, M., Akufo-Addo, C., Yanagawa, Y., and Pachnis, V. (2007). Lhx6 activity is required for the normal migration and specification of cortical interneuron subtypes. J. Neurosci. 27, 3078-3089. doi: 10.1523/JNEUROSCI.3055-06.2007

Liu, J. K., Ghattas, I., Liu, S., Chen, S., and Rubenstein, J. L. (1997). Dlx genes encode DNA-binding proteins that are expressed in an overlapping and sequential pattern during basal ganglia differentiation. Dev. Dyn. 210, 498-512. doi: 10.1002/(SICI)1097-0177(199712)210:4<498::AID-AJA12>3.0.CO;2-3

Lodato, S., Tomassy, G. S., De Leonibus, E., Uzcategui, Y. G., Andolfi, G., Armentano, M., et al. (2011a). Loss of COUP-TFI alters the balance between caudal ganglionic eminence- and medial ganglionic eminence-derived cortical interneurons and results in resistance to epilepsy. J. Neurosci. 31, 4650-4662. doi: 10.1523/JNEUROSCI.6580-10.2011

Lodato, S., Rouaux, C., Quast, K. B., Jantrachotechatchawan, C., Studer, M., Hensch, T. K., et al. (2011b). Excitatory projection neuron subtypes control the distribution of local inhibitory interneurons in the cerebral cortex. Neuron 69, 763-779. doi: 10.1016/j.neuron.2011.01.015

Long, J. E., Cobos, I., Potter, G. B., and Rubenstein, J. L. (2009a). Dlx1\&2 and Mash1 transcription factors control MGE and CGE patterning and differentiation through parallel and overlapping pathways. Cereb. Cortex 19(Suppl. 1), i96-i106. doi: 10.1093/cercor/bhp045

Long, J. E., Swan, C., Liang, W. S., Cobos, I., Potter, G. B., and Rubenstein, J. L. (2009b). Dlx1\&2 and Mash1 transcription factors control striatal patterning and differentiation through parallel and overlapping pathways. J. Comp. Neurol. 512, 556-572. doi: 10.1002/cne.21854

Lopez-Bendito, G., Lujan, R., Shigemoto, R., Ganter, P., Paulsen, O., and Molnar Z. (2003). Blockade of GABA(B) receptors alters the tangential migration of cortical neurons. Cereb. Cortex 13, 932-942. doi: 10.1093/cercor/13.9.932

Lopez-Bendito, G., Sanchez-Alcaniz, J. A., Pla, R., Borrell, V., Pico, E., Valdeolmillos, M., et al. (2008). Chemokine signaling controls intracortical migration and final distribution of GABAergic interneurons. J. Neurosci. 28, 1613-1624. doi: 10.1523/JNEUROSCI.4651-07.2008

LoTurco, J. J., Owens, D. F., Heath, M. J., Davis, M. B., and Kriegstein, A. R. (1995). GABA and glutamate depolarize cortical progenitor cells and inhibit DNA synthesis. Neuron 15, 1287-1298.

Luccardini, C., Hennekinne, L., Viou, L., Yanagida, M., Murakami, F., Kessaris, N., et al. (2013). N-cadherin sustains motility and polarity of future cortical interneurons during tangential migration. J. Neurosci. 33, 18149-18160. doi: 10.1523/JNEUROSCI.0593-13.2013

Luk, K. C., Kennedy, T. E., and Sadikot, A. F. (2003). Glutamate promotes proliferation of striatal neuronal progenitors by an NMDA receptor-mediated mechanism. J. Neurosci. 23, 2239-2250.

Lukaszewicz, A., Savatier, P., Cortay, V., Kennedy, H., and Dehay, C. (2002). Contrasting effects of basic fibroblast growth factor and neurotrophin 3 on cell cycle kinetics of mouse cortical stem cells. J. Neurosci. 22, 6610-6622.

Lyons, M. R., Schwarz, C. M., and West, A. E. (2012). Members of the myocyte enhancer factor 2 transcription factor family differentially regulate Bdnf transcription in response to neuronal depolarization. J. Neurosci. 32, 12780-12785. doi: 10.1523/JNEUROSCI.0534-12.2012

Lysko, D. E., Putt, M., and Golden, J. A. (2014). SDF1 reduces interneuron leading process branching through dual regulation of actin and microtubules. J. Neurosci. 34, 4941-4962. doi: 10.1523/JNEUROSCI.4351-12.2014

Ma, W., and Barker, J. L. (1995). Complementary expressions of transcripts encoding GAD67 and GABAA receptor alpha 4, beta 1, and gamma 1 subunits in the proliferative zone of the embryonic rat central nervous system. J. Neurosci. 15, 2547-2560.

Ma, T., Zhang, Q., Cai, Y., You, Y., Rubenstein, J. L., and Yang, Z. (2012). A subpopulation of dorsal lateral/caudal ganglionic eminence-derived neocortical 
interneurons expresses the transcription factor Sp8. Cereb. Cortex 22, 2120-2130. doi: 10.1093/cercor/bhr296

Ma, T., Wang, C., Wang, L., Zhou, X., Tian, M., Zhang, Q., et al. (2013). Subcortical origins of human and monkey neocortical interneurons. Nat. Neurosci. 16, 1588-1597. doi: 10.1038/nn.3536

Manent, J. B., Jorquera, I., Ben-Ari, Y., Aniksztejn, L., and Represa, A. (2006). Glutamate acting on AMPA but not NMDA receptors modulates the migration of hippocampal interneurons. J. Neurosci. 26, 5901-5909. doi: 10.1523/JNEUROSCI.1033-06.2006

Maric, D., Liu, Q. Y., Maric, I., Chaudry, S., Chang, Y. H., Smith, S. V., et al. (2001). GABA expression dominates neuronal lineage progression in the embryonic rat neocortex and facilitates neurite outgrowth via GABA(A) autoreceptor/Clchannels. J. Neurosci. 21, 2343-2360.

Marillat, V., Cases, O., Nguyen-Ba-Charvet, K. T., Tessier-Lavigne, M., Sotelo, C., and Chedotal, A. (2002). Spatiotemporal expression patterns of slit and robo genes in the rat brain. J. Comp. Neurol. 442, 130-155. doi: 10.1002/cne.10068

Marin, O. (2012). Interneuron dysfunction in psychiatric disorders. Nat. Rev. Neurosci. 13, 107-120. doi: 10.1038/nrn3155

Marin, O., Anderson, S. A., and Rubenstein, J. L. (2000). Origin and molecular specification of striatal interneurons. J. Neurosci. 20, 6063-6076.

Marin, O., Yaron, A., Bagri, A., Tessier-Lavigne, M., and Rubenstein, J. L. (2001). Sorting of striatal and cortical interneurons regulated by semaphorinneuropilin interactions. Science 293, 872-875. doi: 10.1126/science.1061891

Marin, O., Baker, J., Puelles, L., and Rubenstein, J. L. (2002). Patterning of the basal telencephalon and hypothalamus is essential for guidance of cortical projections. Development 129, 761-773.

Marin, O., Plump, A. S., Flames, N., Sanchez-Camacho, C., Tessier-Lavigne, M., and Rubenstein, J. L. (2003). Directional guidance of interneuron migration to the cerebral cortex relies on subcortical Slit1/2-independent repulsion and cortical attraction. Development 130, 1889-1901. doi: 10.1242/dev.00417

Martinez-Cerdeno, V., Noctor, S. C., Espinosa, A., Ariza, J., Parker, P., Orasji, S., et al. (2010). Embryonic MGE precursor cells grafted into adult rat striatum integrate and ameliorate motor symptoms in 6-OHDA-lesioned rats. Cell Stem Cell 6, 238-250. doi: 10.1016/j.stem.2010.01.004

Martini, F. J., and Valdeolmillos, M. (2010). Actomyosin contraction at the cell rear drives nuclear translocation in migrating cortical interneurons. J. Neurosci. 30, 8660-8670. doi: 10.1523/JNEUROSCI.1962-10.2010

Martini, F. J., Valiente, M., Lopez Bendito, G., Szabo, G., Moya, F., Valdeolmillos, M., et al. (2009). Biased selection of leading process branches mediates chemotaxis during tangential neuronal migration. Development 136, 41-50. doi: $10.1242 /$ dev.025502

Martynoga, B., Morrison, H., Price, D. J., and Mason, J. O. (2005). Foxg1 is required for specification of ventral telencephalon and region-specific regulation of dorsal telencephalic precursor proliferation and apoptosis. Dev. Biol. 283, 113-127. doi: 10.1016/j.ydbio.2005.04.005

McKinsey, G. L., Lindtner, S., Trzcinski, B., Visel, A., Pennacchio, L. A., Huylebroeck, D., et al. (2013). Dlx1\&2-dependent expression of Zfhx1b (Sip1, Zeb2) regulates the fate switch between cortical and striatal interneurons. Neuron 77 , 83-98. doi: 10.1016/j.neuron.2012.11.035

McManus, M. F., Nasrallah, I. M., Pancoast, M. M., Wynshaw-Boris, A., and Golden, J. A. (2004). Lis1 is necessary for normal non-radial migration of inhibitory interneurons. Am. J. Pathol. 165, 775-784. doi: 10.1016/S00029440(10)63340-8

Metin, C., and Godement, P. (1996). The ganglionic eminence may be an intermediate target for corticofugal and thalamocortical axons. J. Neurosci. 16, 3219-3235.

Metin, C., Denizot, J. P., and Ropert, N. (2000). Intermediate zone cells express calcium-permeable AMPA receptors and establish close contact with growing axons. J. Neurosci. 20, 696-708.

Metin, C., Baudoin, J. P., Rakic, S., and Parnavelas, J. G. (2006). Cell and molecular mechanisms involved in the migration of cortical interneurons. Eur. J. Neurosci. 23, 894-900. doi: 10.1111/j.1460-9568.2006.04630.x

Millar, J. K., Christie, S., Semple, C. A., and Porteous, D. J. (2000a). Chromosomal location and genomic structure of the human translin-associated factor $\mathrm{X}$ gene (TRAX; TSNAX) revealed by intergenic splicing to DISC1, a gene disrupted by a translocation segregating with schizophrenia. Genomics 67, 69-77. doi: 10.1006/geno.2000.6239

Millar, J. K., Wilson-Annan, J. C., Anderson, S., Christie, S., Taylor, M. S., Semple, C. A., et al. (2000b). Disruption of two novel genes by a translocation co-segregating with schizophrenia. Hum. Mol. Genet. 9, 1415-1423. doi: 10.1093/hmg/9.9.1415

Miller, M. W. (1985). Cogeneration of retrogradely labeled corticocortical projection and GABA-immunoreactive local circuit neurons in cerebral cortex. Brain Res. 355, 187-192.

Miyoshi, G., and Fishell, G. (2011). GABAergic interneuron lineages selectively sort into specific cortical layers during early postnatal development. Cereb. Cortex 21, 845-852. doi: 10.1093/cercor/bhq155

Miyoshi, G., Hjerling-Leffler, J., Karayannis, T., Sousa, V. H., Butt, S. J., Battiste, J., et al. (2010). Genetic fate mapping reveals that the caudal ganglionic eminence produces a large and diverse population of superficial cortical interneurons. J. Neurosci. 30, 1582-1594. doi: 10.1523/JNEUROSCI.4515-09.2010

Mountcastle, V. B. (1997). The columnar organization of the neocortex. Brain 120(Pt 4), 701-722.

Nadarajah, B., Alifragis, P., Wong, R. O., and Parnavelas, J. G. (2002). Ventricledirected migration in the developing cerebral cortex. Nat. Neurosci. 5, 218-224. doi: $10.1038 / \mathrm{nn} 813$

Nasrallah, I. M., McManus, M. F., Pancoast, M. M., Wynshaw-Boris, A., and Golden, J. A. (2006). Analysis of non-radial interneuron migration dynamics and its disruption in Lis1+/- mice. J. Comp. Neurol. 496, 847-858. doi: 10.1002/cne.20966

Neddens, J., and Buonanno, A. (2010). Selective populations of hippocampal interneurons express ErbB4 and their number and distribution is altered in ErbB4 knockout mice. Hippocampus 20, 724-744. doi: 10.1002/hipo.20675

Nguyen, L., Rigo, J. M., Rocher, V., Belachew, S., Malgrange, B., Rogister, B., et al. (2001). Neurotransmitters as early signals for central nervous system development. Cell Tissue Res. 305, 187-202. doi: 10.1007/s004410000343

Nguyen, L., Besson, A., Heng, J. I., Schuurmans, C., Teboul, L., Parras, C., et al. (2006). p27kip1 independently promotes neuronal differentiation and migration in the cerebral cortex. Genes Dev. 20, 1511-1524. doi: 10.1101/gad.377106

Ni, C. Y., Murphy, M. P., Golde, T. E., and Carpenter, G. (2001). gamma -Secretase cleavage and nuclear localization of ErbB-4 receptor tyrosine kinase. Science 294, 2179-2181. doi: 10.1126/science.1065412

Nobrega-Pereira, S., Kessaris, N., Du, T., Kimura, S., Anderson, S. A., and Marin, O. (2008). Postmitotic Nkx2-1 controls the migration of telencephalic interneurons by direct repression of guidance receptors. Neuron 59, 733-745. doi: 10.1016/j.neuron.2008.07.024

Ohkubo, Y., Chiang, C., and Rubenstein, J. L. (2002). Coordinate regulation and synergistic actions of BMP4, SHH and FGF8 in the rostral prosencephalon regulate morphogenesis of the telencephalic and optic vesicles. Neuroscience 111, 1-17. doi: 10.1016/S0306-4522(01)00616-9

Ohtani, N., Goto, T., Waeber, C., and Bhide, P. G. (2003). Dopamine modulates cell cycle in the lateral ganglionic eminence. J. Neurosci. 23, 2840-2850.

Oliver, T. G., Grasfeder, L. L., Carroll, A. L., Kaiser, C., Gillingham, C. L., Lin, S. M., et al. (2003). Transcriptional profiling of the Sonic hedgehog response: a critical role for N-myc in proliferation of neuronal precursors. Proc. Natl. Acad. Sci. U.S.A. 100, 7331-7336. doi: 10.1073/pnas.0832317100

Owens, D. F., and Kriegstein, A. R. (2002a). Is there more to GABA than synaptic inhibition? Nat. Rev. Neurosci. 3, 715-727. doi: 10.1038/nrn919

Owens, D. F., and Kriegstein, A. R. (2002b). Developmental neurotransmitters? Neuron 36, 989-991. doi: 10.1016/S0896-6273(02)01136-4

Owens, D. F., Liu, X., and Kriegstein, A. R. (1999). Changing properties of GABA(A) receptor-mediated signaling during early neocortical development. J. Neurophysiol. 82, 570-583.

Pan, Y., Bai, C. B., Joyner, A. L., and Wang, B. (2006). Sonic hedgehog signaling regulates Gli2 transcriptional activity by suppressing its processing and degradation. Mol. Cell. Biol. 26, 3365-3377. doi: 10.1128/MCB.26.9.3365-3377.2006

Parras, C. M., Hunt, C., Sugimori, M., Nakafuku, M., Rowitch, D., and Guillemot, F. (2007). The proneural gene Mash1 specifies an early population of telencephalic oligodendrocytes. J. Neurosci. 27, 4233-4242. doi: 10.1523/JNEUROSCI.0126-07.2007

Pei, Z., Wang, B., Chen, G., Nagao, M., Nakafuku, M., and Campbell, K. (2011). Homeobox genes Gsx1 and Gsx2 differentially regulate telencephalic progenitor maturation. Proc. Natl. Acad. Sci. U.S.A. 108, 1675-1680. doi: 10.1073/pnas.1008824108

Petilla Interneuron Nomenclature, G., Ascoli, G. A., Alonso-Nanclares, L., Anderson, S. A., Barrionuevo, G., Benavides-Piccione, R., et al. (2008). Petilla terminology: nomenclature of features of GABAergic interneurons of the cerebral cortex. Nat. Rev. Neurosci. 9, 557-568. doi: 10.1038/nrn2402 
Petryniak, M. A., Potter, G. B., Rowitch, D. H., and Rubenstein, J. L. (2007). Dlx1 and Dlx2 control neuronal versus oligodendroglial cell fate acquisition in the developing forebrain. Neuron 55, 417-433. doi: 10.1016/j.neuron.2007.06.036

Pilz, G. A., Shitamukai, A., Reillo, I., Pacary, E., Schwausch, J., Stahl, R., et al. (2013). Amplification of progenitors in the mammalian telencephalon includes a new radial glial cell type. Nat. Commun. 4:2125. doi: 10.1038/ncomms3125

Pla, R., Borrell, V., Flames, N., and Marin, O. (2006). Layer acquisition by cortical GABAergic interneurons is independent of Reelin signaling. J. Neurosci. 26, 6924-6934. doi: 10.1523/JNEUROSCI.0245-06.2006

Pleasure, S. J., Anderson, S., Hevner, R., Bagri, A., Marin, O., Lowenstein, D. H., et al. (2000). Cell migration from the ganglionic eminences is required for the development of hippocampal GABAergic interneurons. Neuron 28, 727-740. doi: 10.1016/S0896-6273(00)00149-5

Poitras, L., Ghanem, N., Hatch, G., and Ekker, M. (2007). The proneural determinant MASH1 regulates forebrain Dlx1/2 expression through the $\mathrm{I} 12 \mathrm{~b}$ intergenic enhancer. Development 134, 1755-1765. doi: 10.1242/dev.02845

Polleux, F., Whitford, K. L., Dijkhuizen, P. A., Vitalis, T., and Ghosh, A. (2002). Control of cortical interneuron migration by neurotrophins and PI3-kinase signaling. Development 129, 3147-3160.

Porter, J. A., Young, K. E., and Beachy, P. A. (1996). Cholesterol modification of hedgehog signaling proteins in animal development. Science 274, 255-259.

Powell, E. M., Mars, W. M., and Levitt, P. (2001). Hepatocyte growth factor/scatter factor is a motogen for interneurons migrating from the ventral to dorsal telencephalon. Neuron 30, 79-89. doi: 10.1016/S0896-6273(01)00264-1

Pozas, E., and Ibanez, C. F. (2005). GDNF and GFRalpha1 promote differentiation and tangential migration of cortical GABAergic neurons. Neuron 45, 701-713. doi: 10.1016/j.neuron.2005.01.043

Rallu, M., Machold, R., Gaiano, N., Corbin, J. G., McMahon, A. P., and Fishell, G. (2002). Dorsoventral patterning is established in the telencephalon of mutants lacking both Gli3 and Hedgehog signaling. Development 129, 4963-4974.

Rash, B. G., and Grove, E. A. (2007). Patterning the dorsal telencephalon: a role for sonic hedgehog? J. Neurosci. 27, 11595-11603. doi: 10.1523/JNEUROSCI.320407.2007

Ross, M. E. (2011). Cell cycle regulation and interneuron production. Dev. Neurobiol. 71, 2-9. doi: 10.1002/dneu.20823

Rowitch, D. H., S-Jacques, B., Lee, S. M., Flax, J. D., Snyder, E. Y., and McMahon, A. P. (1999). Sonic hedgehog regulates proliferation and inhibits differentiation of CNS precursor cells. J. Neurosci. 19, 8954-8965.

Rubin, A. N., Alfonsi, F., Humphreys, M. P., Choi, C. K., Rocha, S. F., and Kessaris, N. (2010). The germinal zones of the basal ganglia but not the septum generate GABAergic interneurons for the cortex. J. Neurosci. 30, 12050-12062. doi: 10.1523/JNEUROSCI.6178-09.2010

Ruzhynsky, V. A., McClellan, K. A., Vanderluit, J. L., Jeong, Y., Furimsky, M., Park, D. S., et al. (2007). Cell cycle regulator E2F4 is essential for the development of the ventral telencephalon. J. Neurosci. 27, 5926-5935. doi: 10.1523/JNEUROSCI.1538-07.2007

Rymar, V. V., and Sadikot, A. F. (2007). Laminar fate of cortical GABAergic interneurons is dependent on both birthdate and phenotype. J. Comp. Neurol. 501, 369-380. doi: 10.1002/cne.21250

Sadikot, A. F., Burhan, A. M., Belanger, M. C., and Sasseville, R. (1998). NMDA receptor antagonists influence early development of GABAergic interneurons in the mammalian striatum. Brain Res. Dev. Brain Res. 105, 35-42.

Sanchez-Huertas, C., and Rico, B. (2011). CREB-Dependent Regulation of GAD65 Transcription by BDNF/TrkB in Cortical Interneurons. Cereb. Cortex 21, 777-788. doi: 10.1093/cercor/bhq150

Scaltriti, M., and Baselga, J. (2006). The epidermal growth factor receptor pathway: a model for targeted therapy. Clin. Cancer Res. 12, 5268-5272. doi: 10.1158/1078-0432.CCR-05-1554

Schaar, B. T., and McConnell, S. K. (2005). Cytoskeletal coordination during neuronal migration. Proc. Natl. Acad. Sci. U.S.A. 102, 13652-13657. doi: 10.1073/pnas.0506008102

Schaefer, A. W., Kabir, N., and Forscher, P. (2002). Filopodia and actin arcs guide the assembly and transport of two populations of microtubules with unique dynamic parameters in neuronal growth cones. J. Cell Biol. 158, 139-152. doi: 10.1083/jcb.200203038

Sheth, A. N., and Bhide, P. G. (1997). Concurrent cellular output from two proliferative populations in the early embryonic mouse corpus striatum. J. Comp. Neurol. 383, 220-230.
Shimamura, K., Hartigan, D. J., Martinez, S., Puelles, L., and Rubenstein, J. L. (1995). Longitudinal organization of the anterior neural plate and neural tube. Development 121, 3923-3933.

Shinohara, R., Thumkeo, D., Kamijo, H., Kaneko, N., Sawamoto, K., Watanabe, K., et al. (2012). A role for mDia, a Rho-regulated actin nucleator, in tangential migration of interneuron precursors. Nat. Neurosci. 15, 373-380, S371-S372. doi: $10.1038 / \mathrm{nn} .3020$

Silva, C. G., Metin, C., Fazeli, W., Machado, N. J., Darmopil, S., Launay, P. S., et al. (2013). Adenosine receptor antagonists including caffeine alter fetal brain development in mice. Sci. Transl. Med. 5:197ra104. doi: 10.1126/scitranslmed.3006258

Sjostrom, S. K., Finn, G., Hahn, W. C., Rowitch, D. H., and Kenney, A. M. (2005). The Cdk1 complex plays a prime role in regulating $\mathrm{N}$-myc phosphorylation and turnover in neural precursors. Dev. Cell 9, 327-338. doi: 10.1016/j.devcel.2005.07.014

Smart, I. H. (1976). A pilot study of cell production by the ganglionic eminences of the developing mouse brain. J. Anat. 121, 71-84.

Smith, K. M., Maragnoli, M. E., Phull, P. M., Tran, K. M., Choubey, L., and Vaccarino, F. M. (2014). Fgfr1 inactivation in the mouse telencephalon results in impaired maturation of interneurons expressing parvalbumin. PLoS ONE 9:e103696. doi: 10.1371/journal.pone.0103696

Southwell, D. G., Paredes, M. F., Galvao, R. P., Jones, D. L., Froemke, R. C., Sebe, J. Y., et al. (2012). Intrinsically determined cell death of developing cortical interneurons. Nature 491, 109-113. doi: 10.1038/nature11523

Spillane, M., Ketschek, A., Jones, S. L., Korobova, F., Marsick, B., Lanier, L., et al. (2011). The actin nucleating Arp2/3 complex contributes to the formation of axonal filopodia and branches through the regulation of actin patch precursors to filopodia. Dev. Neurobiol. 71, 747-758. doi: 10.1002/dneu.20907

Spoelgen, R., Hammes, A., Anzenberger, U., Zechner, D., Andersen, O. M., Jerchow, B., et al. (2005). LRP2/megalin is required for patterning of the ventral telencephalon. Development 132, 405-414. doi: 10.1242/dev.01580

Stanco, A., Szekeres, C., Patel, N., Rao, S., Campbell, K., Kreidberg, J. A., et al. (2009). Netrin-1-alpha3betal integrin interactions regulate the migration of interneurons through the cortical marginal zone. Proc. Natl. Acad. Sci. U.S.A. 106, 7595-7600. doi: 10.1073/pnas.0811343106

Steinecke, A., Gampe, C., Nitzsche, F., and Bolz, J. (2014a). DISC1 knockdown impairs the tangential migration of cortical interneurons by affecting the actin cytoskeleton. Front. Cell. Neurosci. 8:190. doi: 10.3389/fncel.2014.00190

Steinecke, A., Gampe, C., Zimmer, G., Rudolph, J., and Bolz, J. (2014b). EphA/ephrin A reverse signaling promotes the migration of cortical interneurons from the medial ganglionic eminence. Development 141, 460-471. doi: 10.1242/dev.101691

Storm, E. E., Garel, S., Borello, U., Hebert, J. M., Martinez, S., McConnell, S. K., et al. (2006). Dose-dependent functions of Fgf8 in regulating telencephalic patterning centers. Development 133, 1831-1844. doi: 10.1242/dev.02324

Stumm, R., Kolodziej, A., Schulz, S., Kohtz, J. D., and Hollt, V. (2007). Patterns of SDF-1alpha and SDF-1gamma mRNAs, migration pathways, and phenotypes of CXCR4-expressing neurons in the developing rat telencephalon. J. Comp. Neurol. 502, 382-399. doi: 10.1002/cne.21336

Sussel, L., Marin, O., Kimura, S., and Rubenstein, J. L. (1999). Loss of Nkx2.1 homeobox gene function results in a ventral to dorsal molecular respecification within the basal telencephalon: evidence for a transformation of the pallidum into the striatum. Development 126, 3359-3370.

Tanaka, T., Serneo, F. F., Higgins, C., Gambello, M. J., Wynshaw-Boris, A., and Gleeson, J. G. (2004). Lis1 and doublecortin function with dynein to mediate coupling of the nucleus to the centrosome in neuronal migration. J. Cell Biol. 165, 709-721. doi: 10.1083/jcb.200309025

Tanaka, D. H., Mikami, S., Nagasawa, T., Miyazaki, J., Nakajima, K., and Murakami, F. (2010). CXCR4 is required for proper regional and laminar distribution of cortical somatostatin-, calretinin-, and neuropeptide Y-expressing GABAergic interneurons. Cereb. Cortex 20, 2810-2817. doi: 10.1093/cercor/bhq027

Tao, R., Li, C., Zheng, Y., Qin, W., Zhang, J., Li, X., et al. (2007). Positive association between SIAT8B and schizophrenia in the Chinese Han population. Schizophr. Res. 90, 108-114. doi: 10.1016/j.schres.2006.09.029

Theil, T., Dominguez-Frutos, E., and Schimmang, T. (2008). Differential requirements for Fgf3 and Fgf8 during mouse forebrain development. Dev. Dyn. 237, 3417-3423. doi: 10.1002/dvdy.21765 
Thomas, S. M., and Brugge, J. S. (1997). Cellular functions regulated by Src family kinases. Annu. Rev. Cell Dev. Biol. 13, 513-609. doi: 10.1146/annurev.cellbio.13.1.513

Tiveron, M. C., Rossel, M., Moepps, B., Zhang, Y. L., Seidenfaden, R., Favor, J., et al. (2006). Molecular interaction between projection neuron precursors and invading interneurons via stromal-derived factor 1 (CXCL12)/CXCR4 signaling in the cortical subventricular zone/intermediate zone. J. Neurosci. 26, 13273-13278. doi: 10.1523/JNEUROSCI.4162-06.2006

Tivodar, S., Kalemaki, K., Kounoupa, Z., Vidaki, M., Theodorakis, K., Denaxa, M., et al. (2014). Rac-GTPases regulate microtubule stability and axon growth of cortical GABAergic interneurons. Cereb. Cortex. doi: 10.1093/cercor/bhu037. [Epub ahead of print].

Toritsuka, M., Kimoto, S., Muraki, K., Landek-Salgado, M. A., Yoshida, A., Yamamoto, N., et al. (2013). Deficits in microRNA-mediated Cxcr4/Cxcl12 signaling in neurodevelopmental deficits in a 22q11 deletion syndrome mouse model. Proc. Natl. Acad. Sci. U.S.A. 110, 17552-17557. doi: 10.1073/pnas. 1312661110

Trimarchi, J. M., and Lees, J. A. (2002). Sibling rivalry in the E2F family. Nat. Rev. Mol. Cell Biol. 3, 11-20. doi: 10.1038/nrm714

Tsai, J. W., Bremner, K. H., and Vallee, R. B. (2007). Dual subcellular roles for LIS1 and dynein in radial neuronal migration in live brain tissue. Nat. Neurosci. 10, 970-979. doi: 10.1038/nn1934

Tuncdemir, S. N., Fishell, G., and Batista-Brito, R. (2014). miRNAs are essential for the survival and maturation of cortical interneurons. Cereb. Cortex. doi: 10.1093/cercor/bht426. [Epub ahead of print].

Uchida, Y., Ohshima, T., Sasaki, Y., Suzuki, H., Yanai, S., Yamashita, N., et al. (2005). Semaphorin3A signalling is mediated via sequential Cdk5 and GSK3beta phosphorylation of CRMP2: implication of common phosphorylating mechanism underlying axon guidance and Alzheimer's disease. Genes Cells 10, 165-179. doi: 10.1111/j.1365-2443.2005.00827.x

Valcanis, H., and Tan, S. S. (2003). Layer specification of transplanted interneurons in developing mouse neocortex. J. Neurosci. 23, 5113-5122.

Vidaki, M., Tivodar, S., Doulgeraki, K., Tybulewicz, V., Kessaris, N., Pachnis, V., et al. (2012). Rac1-dependent cell cycle exit of MGE precursors and GABAergic interneuron migration to the cortex. Cereb. Cortex 22, 680-692. doi: 10.1093/cercor/bhr145

Wahl, S., Barth, H., Ciossek, T., Aktories, K., and Mueller, B. K. (2000). Ephrin-A5 induces collapse of growth cones by activating Rho and Rho kinase. J. Cell Biol. $149,263-270$.

Wang, Y., Dye, C. A., Sohal, V., Long, J. E., Estrada, R. C., Roztocil, T., et al. (2010). Dlx5 and Dlx6 regulate the development of parvalbumin-expressing cortical interneurons. J. Neurosci. 30, 5334-5345. doi: 10.1523/JNEUROSCI.596309.2010

Wang, Y., Li, G., Stanco, A., Long, J. E., Crawford, D., Potter, G. B., et al. (2011). CXCR4 and CXCR7 have distinct functions in regulating interneuron migration. Neuron 69, 61-76. doi: 10.1016/j.neuron.2010.12.005

Weaver, A. M., Karginov, A. V., Kinley, A. W., Weed, S. A., Li, Y., Parsons, J. T., et al. (2001). Cortactin promotes and stabilizes Arp2/3-induced actin filament network formation. Curr. Biol. 11, 370-374.

Weed, S. A., and Parsons, J. T. (2001). Cortactin: coupling membrane dynamics to cortical actin assembly. Oncogene 20, 6418-6434. doi: 10.1038/sj.onc.1204783

West, A. E., and Greenberg, M. E. (2011). Neuronal activity-regulated gene transcription in synapse development and cognitive function. Cold Spring Harb Perspect Biol 3. doi: 10.1101/cshperspect.a005744

Wonders, C. P., and Anderson, S. A. (2006). The origin and specification of cortical interneurons. Nat. Rev. Neurosci. 7, 687-696. doi: 10.1038/nrn1954

Wonders, C. P., Taylor, L., Welagen, J., Mbata, I. C., Xiang, J. Z., and Anderson, S. A. (2008). A spatial bias for the origins of interneuron subgroups within the medial ganglionic eminence. Dev. Biol. 314, 127-136. doi: 10.1016/j.ydbio.2007.11.018

Xu, Q., Cobos, I., De La Cruz, E., Rubenstein, J. L., and Anderson, S. A. (2004). Origins of cortical interneuron subtypes. J. Neurosci. 24, 2612-2622. doi: 10.1523/JNEUROSCI.5667-03.2004

Xu, Q., Tam, M., and Anderson, S. A. (2008). Fate mapping Nkx2.1-lineage cells in the mouse telencephalon. J. Comp. Neurol. 506, 16-29. doi: 10.1002/cne.21529
Xu, Q., Guo, L., Moore, H., Waclaw, R. R., Campbell, K., and Anderson, S. A. (2010). Sonic hedgehog signaling confers ventral telencephalic progenitors with distinct cortical interneuron fates. Neuron 65, 328-340. doi: 10.1016/j.neuron.2010.01.004

Yabut, O., Renfro, A., Niu, S., Swann, J. W., Marin, O., and D'Arcangelo, G. (2007). Abnormal laminar position and dendrite development of interneurons in the reeler forebrain. Brain Res. 1140, 75-83. doi: 10.1016/j.brainres.2005. 09.070

Yau, H. J., Wang, H. F., Lai, C., and Liu, F. C. (2003). Neural development of the neuregulin receptor ErbB4 in the cerebral cortex and the hippocampus: preferential expression by interneurons tangentially migrating from the ganglionic eminences. Cereb. Cortex 13, 252-264.

Yoneda, A., and Couchman, J. R. (2003). Regulation of cytoskeletal organization by syndecan transmembrane proteoglycans. Matrix Biol. 22, 25-33.

Yozu, M., Tabata, H., and Nakajima, K. (2004). Birth-date dependent alignment of GABAergic neurons occurs in a different pattern from that of non-GABAergic neurons in the developing mouse visual cortex. Neurosci. Res. 49, 395-403. doi: 10.1016/j.neures.2004.05.005

Yozu, M., Tabata, H., and Nakajima, K. (2005). The caudal migratory stream: a novel migratory stream of interneurons derived from the caudal ganglionic eminence in the developing mouse forebrain. J. Neurosci. 25, 7268-7277. doi: 10.1523/JNEUROSCI.2072-05.2005

Yun, K., Fischman, S., Johnson, J., Hrabe de Angelis, M., Weinmaster, G., and Rubenstein, J. L. (2002). Modulation of the notch signaling by Mash1 and Dlx1/2 regulates sequential specification and differentiation of progenitor cell types in the subcortical telencephalon. Development 129, 5029-5040.

Yun, K., Garel, S., Fischman, S., and Rubenstein, J. L. (2003). Patterning of the lateral ganglionic eminence by the Gsh1 and Gsh2 homeobox genes regulates striatal and olfactory bulb histogenesis and the growth of axons through the basal ganglia. J. Comp. Neurol. 461, 151-165. doi: 10.1002/cne.10685

Zhang, X. F., Schaefer, A. W., Burnette, D. T., Schoonderwoert, V. T., and Forscher, P. (2003). Rho-dependent contractile responses in the neuronal growth cone are independent of classical peripheral retrograde actin flow. Neuron 40, 931-944.

Zhang, W., Kang, J. S., Cole, F., Yi, M. J., and Krauss, R. S. (2006). Cdo functions at multiple points in the Sonic Hedgehog pathway, and Cdo-deficient mice accurately model human holoprosencephaly. Dev. Cell 10, 657-665. doi: 10.1016/j.devcel.2006.04.005

Zhao, Y., Marin, O., Hermesz, E., Powell, A., Flames, N., Palkovits, M., et al. (2003). The LIM-homeobox gene Lhx8 is required for the development of many cholinergic neurons in the mouse forebrain. Proc. Natl. Acad. Sci. U.S.A. 100, 9005-9010. doi: 10.1073/pnas.1537759100

Zhao, Y., Flandin, P., Long, J. E., Cuesta, M. D., Westphal, H., and Rubenstein, J. L. (2008). Distinct molecular pathways for development of telencephalic interneuron subtypes revealed through analysis of Lhx6 mutants. J. Comp. Neurol. 510, 79-99. doi: 10.1002/cne.21772

Zimmer, G., Garcez, P., Rudolph, J., Niehage, R., Weth, F., Lent, R., et al. (2008). Ephrin-A5 acts as a repulsive cue for migrating cortical interneurons. Eur. J. Neurosci. 28, 62-73. doi: 10.1111/j.1460-9568.2008.06320.x

Zimmer, G., Rudolph, J., Landmann, J., Gerstmann, K., Steinecke, A., Gampe, C., et al. (2011). Bidirectional ephrinB3/EphA4 signaling mediates the segregation of medial ganglionic eminence- and preoptic area-derived interneurons in the deep and superficial migratory stream. J. Neurosci. 31, 18364-18380. doi: 10.1523/JNEUROSCI.4690-11.2011

Conflict of Interest Statement: The authors declare that the research was conducted in the absence of any commercial or financial relationships that could be construed as a potential conflict of interest.

Copyright (C) 2015 Peyre, Silva and Nguyen. This is an open-access article distributed under the terms of the Creative Commons Attribution License (CC BY). The use, distribution or reproduction in other forums is permitted, provided the original author(s) or licensor are credited and that the original publication in this journal is cited, in accordance with accepted academic practice. No use, distribution or reproduction is permitted which does not comply with these terms. 